\title{
Magnetic titanium/carbon nanotube nanocomposite catalyst for oxidative degradation of Bisphenol A from high saline polycarbonate plant effluent using catalytic wet peroxide oxidation
}

\author{
Seyyed Abbas Mirzaee ${ }^{\mathrm{a}}$, Neamat Jaafarzadeh ${ }^{\mathrm{b}, \mathrm{c}}$, Helder T. Gomes ${ }^{\mathrm{d}, \mathrm{e}}$, Sahand Jorfi ${ }^{\mathrm{b}, \mathrm{c}}$, \\ Mehdi Ahmadi ${ }^{\mathrm{b}, \mathrm{c}, *}$ \\ ${ }^{a}$ Department of Environmental Health Engineering, School of Health, Ilam University of Medical Sciences, Ilam, Iran \\ ${ }^{\mathrm{b}}$ Department of Environmental Health Engineering, Ahvaz Jundishapur University of Medical Sciences, Ahvaz, Iran \\ ${ }^{c}$ Environmental Technologies Research Center, Ahvaz Jundishapur University of Medical Sciences, Ahvaz, Iran \\ ${ }^{\mathrm{d}}$ Centro de Investigação de Montanha (CIMO), Instituto Politécnico de Bragança, 5300-253 Bragança, Portugal \\ ${ }^{\mathrm{e}}$ Laboratory of Separation and Reaction Engineering - Laboratory of Catalysis and Materials (LSRE-LCM), Faculdade de Engenharia, Universidade do Porto, Rua Dr. \\ Roberto Frias, 4200-465 Porto, Portugal
}

\section{H I G H L I G H T S}

- The saline polycarbonate wastewater was treated by catalytic wet peroxide oxidation.

- The magnetite TNT/CNT nanocomposite was developed as CWPO catalyst.

- The complete BPA, $68.78 \%$ of COD and $47.14 \%$ of TOC reduction was obtained in CWPO.

- The reusability of the catalyst shows with slight decline after 4 consecutive runs.

- The biodegradability of treated PCW using CWPO process was improved significantly.

\section{A R T I C L E I N F O}

\section{Keywords:}

Bisphenol A

Magnetite TNT/CNT nanocomposite

Heterogeneous Fenton-like process

Polycarbonate plant wastewater

\section{G R A P H I C A L A B S T R A C T}
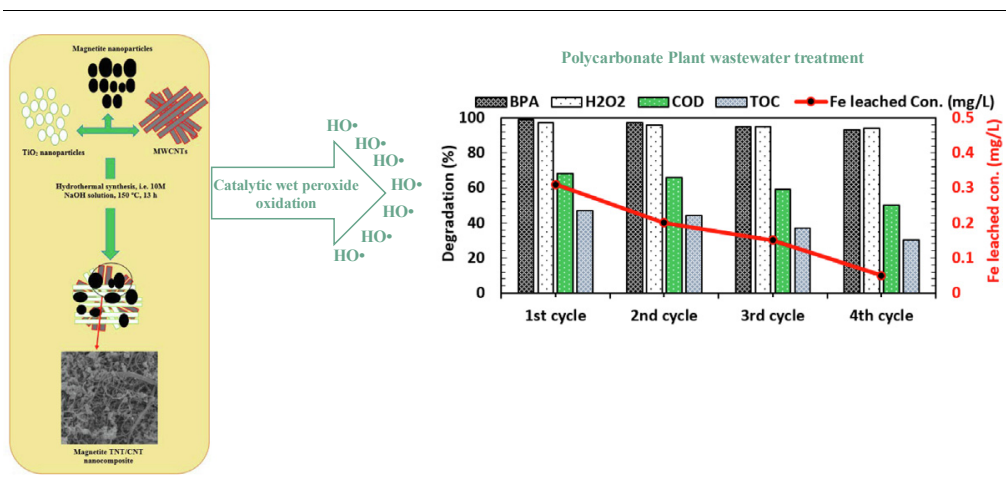

\begin{abstract}
A B S T R A C T
In this study, a magnetic titanium nanotube/carbon nanotube nanocomposite (magnetite TNT@CNT nanocomposite) was developed and its efficiency was evaluated towards oxidative degradation of Bisphenol A (BPA) from high saline polycarbonate plant wastewater (PCW) using catalytic wet peroxide oxidation (CWPO). The characterization of the nanocomposite was performed using XRD, SEM, BET surface area, FT-IR, and VSM analysis. The effects of operating conditions, including solution $\mathrm{pH}, \mathrm{H}_{2} \mathrm{O}_{2}$ dosage, reaction temperature and catalyst loading, were optimized in the CWPO process for degradation of BPA in the PCW. In the best obtained experimental condition, at $\mathrm{pH}$ of $6.30, \mathrm{H}_{2} \mathrm{O}_{2}$ dosage of $2.5 \mathrm{~g} / \mathrm{L}$, temperature of $70{ }^{\circ} \mathrm{C}$ and $100 \mathrm{mg} / \mathrm{L}$ of catalyst dosage, CWPO process exhibits the best catalytic performance with the complete BPA degradation, $68.78 \%$ of COD removal and $47.14 \%$ of TOC reduction for PCW being obtained. The role of hydroxyl radicals in the reaction mechanism was shown by indirect analysis i.e. tert Butanol $(\mathrm{tBuOH})$ scavenging experiment. Under the optimum experimental conditions, the stability and reusability of the nanocomposite was demonstrated with slight decline $(<10 \%$ reduction) in the CWPO after four consecutive runs in terms of its catalytic activity. The fate of organic pollutants in the treated PCW by CWPO was identified by qualitative GC/MS analysis. The biodegradability of the treated PCW increased during the CWPO process with a 4-fold increase of the BOD $\mathrm{BCOD}_{5} / \mathrm{COD}$
\end{abstract}

\footnotetext{
* Corresponding author at: Department of Environmental Health Engineering, Ahvaz Jundishapur University of Medical Sciences, Ahvaz, Iran.

E-mail addresses: htgomes@ipb.pt (H.T. Gomes), sahand369@yahoo.com (S. Jorfi), Ahmadi241@gmail.com (M. Ahmadi).
} 
ratio being obtained, namely from 0.1 (indicating non-biodegradability) to 0.43 (showing biodegradability by means of biological treatment) and AOS and COS were increased to 2.26 and 3.08, respectively. Overall, the CWPO process with magnetite TNT/CNT nanocomposite, due to the simple and easy in-situ catalyst recovery/ separation and good catalytic activity, can be considered as a promising destructive technology for industrial wastewater treatment.

\section{Introduction}

Polycarbonate plant wastewater (PCW) is typically characterized by high levels of aromatic hydrocarbons and phenolic substances, such as Bisphenol A, as well as high concentrations of salinity, inorganic dissolved salts and total dissolved solids (TDS) [1-3]. Bisphenol A (2, 2-bis (4-hydroxyphenyl) propane, BPA), characterized by two phenolic rings joined together through isopropylidene as bridging group, is a main industrial chemical widely used in plastic industry as intermediate in the manufacturing of polycarbonate and in the production of epoxy resins and corrosion-resistant unsaturated polystyrene resins $[4,5]$. The worldwide BPA production is estimated about 5.4 million tons in 2015 and exceeding 3.8 million tons every year $[5,6]$. Due to its wide application and slow biodegradation, BPA concentrations are reported in the influent and effluents of wastewater treatment plants (WWTPs) in the range of $1.0-100 \mu \mathrm{g} / \mathrm{L}$ and $1-100 \mathrm{ng} / \mathrm{L}$, respectively [4-8]. BPA is classified as "moderately toxic" to aquatic organisms and considered an endocrine disrupting chemical (EDC) because of the similar structure with the estrogen receptors. Bearing this in mind, some studies reported that owing to its tumor promoting properties, BPA may be reasonably anticipated to be a human carcinogen $[5,6,9,10]$.

The complexity and toxicity of the presence of highly toxic organic compounds, as well as the high salinity of PCW, justifies the inefficiency of conventional biological treatments. Thus, finding innovative and cost-effective alternative technologies for the treatment of these types of industrial wastewater is of utmost importance. Among the currently available alternative technologies, the so-called advanced oxidation processes (AOPs) have already shown to play a key role in the degradation of organic pollutants in the green wastewater treatment scenario. AOPs technologies are considered among the most efficient water purification technologies based on the ability to generate in-situ highly reactive free radical species (such as $\mathrm{HO}^{\circ}$ and $\mathrm{SO}_{4}{ }^{-}$- radicals) for decomposition of recalcitrant compounds. The advantages of AOPs can be summarized to the simplicity of the required equipment, the operation at mild conditions and the capability to degrade a wide range of organic pollutants to the extent of mineralization [11-17].

In this sense, catalytic wet peroxide oxidation (CWPO) is an AOP based on the transfer of electrons from an appropriate catalyst to hydrogen peroxide $\left(\mathrm{H}_{2} \mathrm{O}_{2}\right)$ molecules in order to accelerate its catalytic decomposition into hydroxide ions $\left(\mathrm{OH}^{-}\right)$and hydroxyl radicals ( $\mathrm{HO}$ ) $\left(\mathrm{E}^{0}=2.73 \mathrm{~V}\right)$, as given in Eq. (1). Hydroxyl radical is considered a robust and non-selective oxidant in the AOPs technologies, responsible by the degradation of a wide range of organic compounds to harmless end-products, such as $\mathrm{CO}_{2}$ and $\mathrm{H}_{2} \mathrm{O}$. CWPO was not only considered an economical viable and low-cost destructive technology, but also able to proceed with simple operation equipment under mild conditions (typically at low temperature and atmospheric pressure) and non-threatening to the environment. CWPO has been successfully applied in the degradation of a huge range of recalcitrant organic contaminants in wastewater [11,18-24].

The classical Fenton oxidation process, one of the well-known and most effective homogenous AOPs, is considered a particular type of CWPO, which in this case, using the specific catalyst at the specific operating conditions, based on Eqs. (2) and (3), the chemical reaction between homogenous $\mathrm{Fe}$ (II) and $\mathrm{H}_{2} \mathrm{O}_{2}$ under strong acidic condition $(\mathrm{pH}=2.5-4)$ results in the formation of $\mathrm{HO}^{\circ}$ radicals.

$\mathrm{H}_{2} \mathrm{O}_{2}+\mathrm{e}^{-} \rightarrow \mathrm{OH}^{-}+\mathrm{HO}$
$\mathrm{H}_{2} \mathrm{O}_{2}+\mathrm{Fe}(\mathrm{II}) \mathrm{HO}+\mathrm{OH}^{-}+\mathrm{Fe}(\mathrm{III})$

$\mathrm{H}_{2} \mathrm{O}_{2}+\mathrm{Fe}(\mathrm{III}) \rightarrow \mathrm{Fe}(\mathrm{II})+\mathrm{HOO}+\mathrm{H}^{+}$

The Fenton process suffer from important shortcomings, including the unavoidable loss of catalyst, requiring to further process the iron sludge generated at the end of the treatment, and a complicated final chemical and physical separation step for recovery or elimination of $\mathrm{Fe}$ (II)/Fe (III) ions in the effluent. Therefore, in order to overcome the abovementioned important shortcomings, application of heterogeneous catalysts have important advantages compared to the homogenous catalyst $[21,24,25]$. Among iron-containing heterogeneous catalysts (such as $\mathrm{Fe}_{3} \mathrm{O}_{4}, \mathrm{Fe}_{2} \mathrm{O}_{3}, \mathrm{Fe}^{0}$ and $\mathrm{FeOOH}$ ), $\mathrm{Fe}_{3} \mathrm{O}_{4}$ magnetic nanoparticles (MNPs) are considered one of the most efficient heterogeneous nanocomposites to use in CWPO $[14,24]$. In a similar mechanism to that shown in Eq. (2), $\mathrm{Fe}_{3} \mathrm{O}_{4}$ MNPs are capable to generate $\mathrm{HO}^{\circ}$ through decomposition of $\mathrm{H}_{2} \mathrm{O}_{2}$. Nevertheless, due to intra-particle interaction, i.e. Van der Waals and intrinsic magnetic interaction, $\mathrm{Fe}_{3} \mathrm{O}_{4} \mathrm{MNPs}$ have a strong tendency for particle agglomeration, leading to a decrease of the surface/volume ratio of the particles, as well as dispersion of their stability in the reaction solution. As a consequence, its catalytic activity is eventually reduced $[24,26,27]$. Taking this into consideration, in the recent two decades, different support materials, such as alumina, pillared clays, zeolites, silica, and ion-exchange resins have been used to prepare transition-metal-supported catalysts, mainly iron, for application in CWPO $[24,28,29]$. However, due to the leaching phenomenon, these catalysts mainly suffer from limited stability $[28,30]$. On the other hand, carbon materials with easily tuned properties, like activated carbons [20,30,31], graphite and graphene-based materials [32,33], activated carbon xerogels [11,21,34], carbon blacks [33], glycerolbased carbon materials [35] and carbon nanotubes (CNTs) [36], have been used as active and efficient catalysts for degradation of pollutants by CWPO, however with lower efficiency compared to metal based catalysts [23]. Among the reported supported catalysts, nanomaterials such as CNTs have attracted attention due to their unique and interesting properties, important for superior catalyst support materials, including their distinctive tubular structure, low mass-transfer limitations, high mechanical strength, superior electrical properties, large specific surface area and relatively high thermal stability in oxidizing conditions [23,36,37]. More recently, titanium dioxide nanotubes (TNTs) were successfully used as efficient nanocomposites in the CWPO/CWAO for oxidative degradation of organic pollutants [4]. According to reported studies, TNTs have also interesting properties, such as high specific surface area and adsorption capacity, good ion-exchange property and low recombination rate by long electron transport distance along the tubular structure $[4,38]$.

Therefore, the synthesis of TNT/CNT porous nanocomposite has gained research interest due to the provided advantages of two nanotubular structures, which could enhance the efficiency of organic pollutants degradation. On the other hand, the synthesis of magnetite TNT/CNT nanocomposite present important features due to the easily separation of the nanocomposite from the reaction solution by an external magnet field and the elimination of the high cost for final chemical and physical separation process. In the present study, a magnetite TNT/CNT nanocomposite was synthesized using an alkaline hydrothermal method and its catalytic activity performance in CWPO for the degradation of BPA, as well as the reductions of chemical oxygen demand (COD), total organic carbon (TOC), and the five-day biochemical oxygen demand $\left(\mathrm{BOD}_{5}\right)$ in the highly toxic and high salinity of PCW 
were assessed.

\section{Materials and methods}

\subsection{Chemicals}

All the materials used in the experiments were of analytical reagent grade and applied without further purification. Double distilled water was used to prepare the experimental solutions. Bisphenol A, (BPA, $\mathrm{C}_{15} \mathrm{H}_{16} \mathrm{O}_{2}, \quad \geq 99 \mathrm{wt} \%$ ), Multi-Walled Carbon Nanotubes (MWCNT, $>99 \%$ carbon basic, OD $=60-100 \mathrm{~nm}$, ID $=5-10 \mathrm{~nm}$, and length $=0.5-500 \mu \mathrm{m}$ ), Titanium (IV) oxide (anatase, nanopowders, $<$ $25 \mathrm{~nm}$ particle size, 99.7\%), Titanium (IV) oxysulfate $\left(\mathrm{TiOSO}_{4} \cdot \mathrm{xH}_{2} \mathrm{O}\right.$, $15 \mathrm{wt} \%$ in diluted sulphuric acid, 99.99\%) and tert-butanol (tBuOH) were purchased from Sigma-Aldrich Company. HPLC-grade Acetonitrile $\left(\mathrm{CH}_{3} \mathrm{CN}, 99.9 \%\right)$ and water $\left(\mathrm{H}_{2} \mathrm{O}, 99.9 \%\right)$ were obtained from Samchun Company. Hydrogen peroxide $\left(\mathrm{H}_{2} \mathrm{O}_{2}, 30 \% \mathrm{w} / \mathrm{v}\right)$, mercury (II) sulfate $\left(\mathrm{HgSO}_{4}, 99 \mathrm{wt} \%\right)$ and potassium dichromate $(99.5 \mathrm{wt} \%)$, silver nitrate (99.8 wt\%), silver sulfate, iron (II) sulfate heptahydrate $\left(\mathrm{FeSO}_{4} \cdot 7 \mathrm{H}_{2} \mathrm{O}\right)$, sodium sulfate $\left(\mathrm{Na}_{2} \mathrm{SO}_{4}\right)$, sodium sulphite, ethanol absolute (99.8 wt\%), sodium hydroxide $(\mathrm{NaOH})$, nitric acid $\left(\mathrm{HNO}_{3}\right)$ and hydrochloric acid ( $\mathrm{HCl})$ were purchased from Merck Co. (Darmstadt, Germany). Ultrapure water was prepared by using a Milli-Q water purification system (Millipore, Bedford, MA, USA).

\subsection{Real PCW from a petrochemical industrial zone}

The real polycarbonate and epoxy-resin effluent considered in this study was collected from a petrochemical plant located in the Mahshahr petrochemical industrial zone, Khuzestan province in the southwest of Iran. The polycarbonate effluent, whose properties are summarized in Table 1, consists of high quantity of raw materials used in the petrochemical unit, such as Bisphenol A and other phenolic derivatives, and various salts used in the manufacturing line. Therefore, the final effluent is characterized by high TDS concentration, highly toxic organic matter, low biodegradability and high toxicity potential. In order to remove the suspended solids that would interfere in the subsequent experiments, the raw wastewater was filtered using Whatman filter paper $(0.45 \mu \mathrm{m})$, then its characteristics were determined.

\subsection{Magnetic TNT/CNT nanocomposite}

\subsubsection{Synthesis of $\mathrm{Fe}_{3} \mathrm{O}_{4}$ nanoparticles}

$\mathrm{Fe}_{3} \mathrm{O}_{4}$ MNPs were synthesized by in situ chemical co-precipitation of $\mathrm{Fe}(\mathrm{II})$ and $\mathrm{Fe}(\mathrm{III})$ in an alkaline solution under nitrogen atmosphere $[39,40]$. For that purpose, distilled water was deaerated during $20 \mathrm{~min}$ with nitrogen gas under vigorous stirring. Then, $10 \mathrm{mM}$ of ferrous sulfate was prepared by dissolution of $2.78 \mathrm{~g} \mathrm{FeSO}_{4}$ in $100 \mathrm{~mL}$ of distilled water and the solution was mixed on a magnetic stirrer for $45 \mathrm{~min}$ at $80 \pm 1{ }^{\circ} \mathrm{C}$. At this point, $10 \mathrm{~mL}$ of a $10 \% \mathrm{NaOH}$ solution was added drop wise for $5 \mathrm{~min}$ to reach a $\mathrm{pH}$ of 10 and to precipitate the black color hydrated iron oxides by mixing on a magnetic stirrer. Then, the suspension was vigorously mixed at $100^{\circ} \mathrm{C}$ for $1 \mathrm{~h}$. The suspension was cooled at room temperature. The possible residues of the precursors used in the synthesis of the catalyst were washed-out with distilled water and ethanol until its $\mathrm{pH}$ reach the neutrality. The catalyst was separated using a simple external magnetic procedure. The catalyst was then dried in an oven at $105^{\circ} \mathrm{C}$ for $6 \mathrm{~h}$, resulting in magnetite $\left(\mathrm{Fe}_{3} \mathrm{O}_{4}\right)$ materials. This catalyst was then stored in an air tight container for subsequent experiments. In the case of $\mathrm{CNT} / \mathrm{Fe}_{3} \mathrm{O}_{4}$ and $\mathrm{TNT} / \mathrm{Fe}_{3} \mathrm{O}_{4}$ catalysts, the desired amounts of CNTs $(0.5 \mathrm{~g})$ and TNTs $(1 \mathrm{~g})$ were separately added to the suspension during the synthesis of $\mathrm{Fe}_{3} \mathrm{O}_{4}$ MNPs.

\subsubsection{Synthesis of titanate nanotubes}

$\mathrm{TiO}_{2}$-based nanotubes (TNTs) were synthesized by hydrothermal synthesis using a similar procedure to that reported by Kasuga et al.
[41] and Erjavec et al. [42]. $\mathrm{TiO}_{2}$ powder (anatase) ( $2 \mathrm{~g}$ ) was totally dispersed in $150 \mathrm{~mL}$ of a $10 \mathrm{M} \mathrm{NaOH}$ aqueous solution by ultrasonication. The suspension was placed in a Teflon-lined autoclave, with up to $75 \%$ of its volume filled with the reaction mixture, and heated up at $130{ }^{\circ} \mathrm{C}$ for at least $24 \mathrm{~h}$. Then, the filtration process was used to separate the resulting white precipitates from the reaction solution. The white precipitates were washed several times with deionized water. In the next step, to accomplish the proton exchange mechanism, the wet cakes were dispersed into $500 \mathrm{~mL}$ of a $0.1 \mathrm{M} \mathrm{HCl}$ solution and kept under room temperature for $24 \mathrm{~h}$. The $\mathrm{HCl}$ treatment process was repeated for at least three times, and each day the fresh $0.1 \mathrm{M} \mathrm{HCl}$ solution was used and followed by neutralization with deionized water. After that, the wet cakes were dried in vacuum under cryogenic conditions to remove adsorbed water without changing the structure of the as-synthesized materials. Finally, the synthesized materials were heat-treated at $600{ }^{\circ} \mathrm{C}$ for $1 \mathrm{~h}$ in air and then stored in an air tight container for subsequent experiments.

\subsubsection{MWCNT functionalization}

Prior to the nanocomposite synthesis, the MWCNT were first functionalized by acid treatment. The MWCNT were suspended in concentrated nitric acid, sonicated and refluxed at $80^{\circ} \mathrm{C}$ for $20 \mathrm{~h}$. Then, the samples were filtered, continuously washed with distilled water until neutrality and finally dried at $110^{\circ} \mathrm{C}$ for $12 \mathrm{~h}$ in oven. This functionalization step introduces oxygenated surface groups onto the MWCNT surface and resulted in better CNT dispersion in aqueous solution.

\subsubsection{Magnetic TNT/CNT nanocomposite}

The hydrothermal method with a concentrated alkali solution, as schematically depicted in Fig. 1, was also used to prepare the magnetic TNT/CNT nanocomposite according to the procedure reported in previous studies $[38,43,44]$ with some modifications. For that purpose, $1 \mathrm{~g}$ of $\mathrm{TiO}_{2}$ powder (anatase) was fully dispersed in $80 \mathrm{~mL}$ of a $10 \mathrm{M} \mathrm{NaOH}$ aqueous solution and mixed for $3 \mathrm{~h}$ on the magnetic stirrer. After that, a desired amount of magnetite $\left(\mathrm{Fe}_{3} \mathrm{O}_{4}\right)(3 \mathrm{~g})$ and commercial CNTs $(0.5 \mathrm{~g})$ were added to the aqueous solution and dispersed to achieve a uniform suspension by ultrasonic homogenization. In the subsequent step, the suspension was transferred into a Teflon-lined autoclave and hydrothermally crystallized for $13 \mathrm{~h}$ in oven at $150^{\circ} \mathrm{C}$. After the performed reaction, the suspension was cooled at room temperature and the precipitate separated by filtration, washed several times and treated in a $0.1 \mathrm{M} \mathrm{HCl}$ solution for $24 \mathrm{~h}$ in order to promote a proton exchange mechanism until the $\mathrm{pH}$ of the precipitate to about 8 was achieved. Then, the precipitate was dispersed in ethanol for $30 \mathrm{~min}$ in an ultrasonic homogenizer. The samples were further dried overnight in a vacuum oven at $80^{\circ} \mathrm{C}$ and then calcined at $600^{\circ} \mathrm{C}$ for $2 \mathrm{~h}$ in air, the magnetic TNT/CNT nanocomposite being obtained.

\section{Table 1}

Characteristics of filtered raw high saline PCW, determined in triplicate measurements.

\begin{tabular}{lll}
\hline Parameter & Value & Unit \\
\hline BPA (Bisphenol A) & $50 \pm 2$ & $\mathrm{mgL}^{-1}$ \\
COD (Chemical oxygen demand) & $1650 \pm 25$ & $\mathrm{mgL}^{-1}$ \\
BOD 5 (Biochemical oxygen demand) & $255 \pm 5$ & $\mathrm{mgL}^{-1}$ \\
BOD $_{5} /$ COD & $0.15 \pm 0.02$ & - \\
Bicarbonate & $10345 \pm 155$ & $\mathrm{mgL}^{-1}$ \\
pH at $25^{\circ} \mathrm{C}$ & $8.6 \pm 0.8$ & Sorensen scale \\
Conductivity & $49510 \pm 580$ & $\mu \mathrm{cm}$ \\
Chlorides & $14395 \pm 15$ & $\mathrm{mgL}^{-1}$ \\
TOC (Total organic carbon) & $842 \pm 110$ & $\mathrm{mgL}^{-1}$ \\
TSS (Total suspended solids) & $63 \pm 7$ & $\mathrm{mgL}^{-1}$ \\
TDS (Total dissolved solids) & $25500 \pm 14700$ & $\mathrm{mgL}^{-1}$ \\
Turbidity & $24 \pm 8$ & $\mathrm{NTU}^{-1}$ \\
Appearance & Yellow & - \\
\hline
\end{tabular}




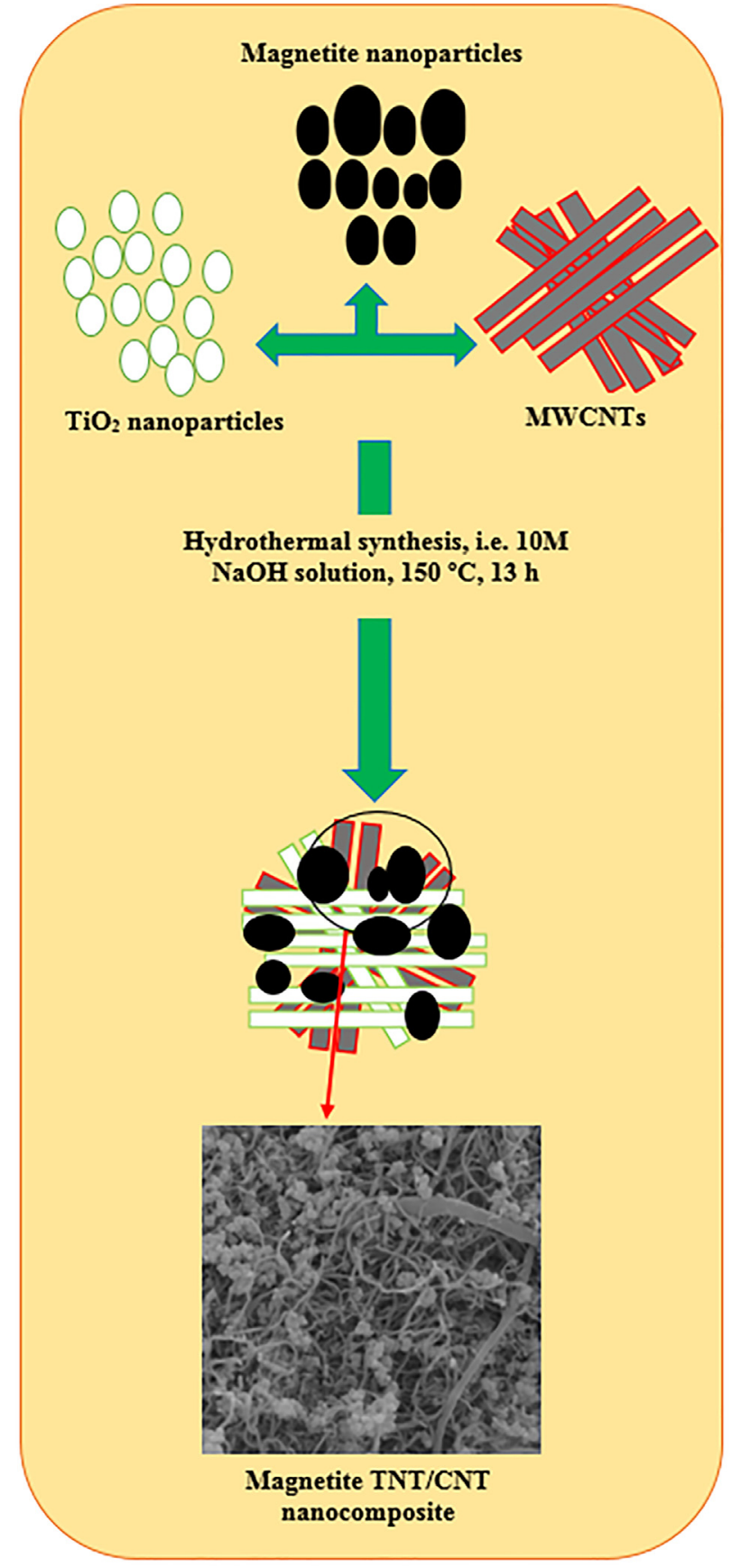

Fig. 1. Schematic of the hydrothermal synthesis of magnetite TNT/CNT nanocomposite.

\subsection{Characterization of the magnetic TNT/CNT nanocomposite}

Powder X-ray diffraction (XRD) spectra was performed at $25^{\circ} \mathrm{C}$ on a X-ray diffractometer (PAN analytical Co. X'pert PRO, UK) using a monochromatized $\mathrm{Cu} k \alpha$ radiation $(\lambda=1.54056 \AA$ Á) by the $2 \theta$ scanning range of $20-80^{\circ}$ to assess the structural characterization of the as-synthesized samples. The functional groups on the surfaces of the catalyst were determined using Fourier transform infrared spectroscopy (FT-IR) (Perkin-Elmer, USA) at room temperature under dry air by the $\mathrm{KBr}$ pellets method. The spectra were prepared in the range of $400-4000 \mathrm{~cm}^{-1}$. The surface morphology and structural properties of the as-synthesized samples were examined using a field emission scanning electron microscopy (FESEM) (Tescan, Mira3, Czech Republic) equipped with an Energy-dispersive X-ray spectroscopy
(EDX) (PHILIPS, XL-30, Netherlands). The Brunauer-Emmett-Teller (BET) specific surface area and pore volume of the nanocomposite were determined using $\mathrm{N}_{2}$ adsorption/desorption isotherms at $77 \mathrm{~K}$ (Quantachrome, NOVA 4200e adsorption analyser). Pore size distribution was calculated by the BJH (Barrett, Joyner\& Halenda) method. In order to assess the magnetic characterization, magnetic properties of the as-prepared catalysts were examined by a Vibrating Sample Magnetometer (VSM) (7400, Lakeshore, USA) at room temperature $\left(25 \pm 1{ }^{\circ} \mathrm{C}\right)$.

\subsection{CWPO experiments}

CWPO experiments were carried out in batch wise mode at ambient pressure in a well-stirred glass reactor $(400 \mathrm{rpm}, 500 \mathrm{~mL})$ equipped with a thermostatic water bath with temperature control. The glass reactor was loaded with $400 \mathrm{~mL}$ of PCW upon stabilization at the desired temperature. The solution $\mathrm{pH}$ was adjusted when necessary, using $\mathrm{HCl}$ and $\mathrm{NaOH}(0.1 \mathrm{~mol} / \mathrm{L})$, and the experiments being then allowed to proceed freely without further conditioning of $\mathrm{pH}$. After the initial $\mathrm{pH}$ adjustment, the given volume of $\mathrm{H}_{2} \mathrm{O}_{2}(30 \mathrm{wt} \%)$ was injected into the system, in order to reach the desired concentration, then the pre-defined catalyst load was added to the aqueous solution after complete homogenization of the solution. This moment was considered as $\mathrm{t}_{0}=0$ min. Pure adsorption runs were also carried out to determine the possible contribution of adsorption and catalytic degradation separately for BPA degradation by CWPO experiments. In this series of CWPO experiments, the equivalent amount of ultrapure water was used instead of $\mathrm{H}_{2} \mathrm{O}_{2}$. The possible non-catalytic oxidation promoted by $\mathrm{H}_{2} \mathrm{O}_{2}$ was also assessed in the series of experiments without presence of any catalyst. The selected experiments were carried out in triplicate and the average values with the error of analysis less than $\pm 0.5 \%$ are reported.

\subsection{Analytical procedures}

The concentration of BPA was analyzed by high performance liquid chromatography (HPLC, KNAUER, Germany) equipped with a 2500 ultraviolet (UV) wavelength detector and a C18 (100-5) column $(4.6 \mathrm{~mm} \times 250 \mathrm{~mm}$, with $5 \mu \mathrm{m}$ particle size) as stationary phase, maintained at $35^{\circ} \mathrm{C}$ in the oven. The UV detection wavelength for BPA was $214 \mathrm{~nm}$. The mobile phase in an isocratic method was a mixture of Millipore water/acetonitrile with a 50:50 ratio at the flow rate of $1 \mathrm{~mL} /$ min. Before injection of the samples, small aliquots were periodically withdrawn from the aqueous solution and, in order to end the reaction and consume residual $\mathrm{H}_{2} \mathrm{O}_{2}$ in the aliquot, an excess of sodium sulphite was quickly added. $100 \mu \mathrm{L}$ sample was filtered by Cellulose Acetate (CA) syringe filter $(0.22 \mu \mathrm{m})$ and manually injected into the HPLC. Under these conditions, the retention time for BPA was $8.5 \mathrm{~min}$. The calibration curve at ten levels of BPA was performed $(0.01-50.0 \mathrm{mg} / \mathrm{L})$ and the obtained R-squared for the calibration curve of BPA was 0.99. The limit of detection was $0.01 \mathrm{mg} / \mathrm{L}$ and the limit of quantification was $0.1 \mathrm{mg} / \mathrm{L}$.

The samples were also analyzed with an Agilent 7890 gas chromatograph with a 5975 single quadrupole mass spectrometer (Agilent, USA) (GC-MS analysis), in order to qualitative analyze the effluent constituents and by-products formed after CWPO. Separation was achieved with a HP-5MS capillary column (30 $\mathrm{m} \times 0.25 \mathrm{~mm} \times 0.25 \mu \mathrm{m}$, film thickness; Agilent, USA, $5 \%$ phenyl $-95 \%$ Methyl Siloxane phase). The sample was injected into the instrument at a splitting ratio of $10: 1$ in splitless mode at $280^{\circ} \mathrm{C}$. The carrier gas (Helium) was fed with constant flow rate of $1 \mathrm{~mL} / \mathrm{min}$. For optimal chromatographic separation, the rate temperature program of the oven was as follows: an initial temperature of $40^{\circ} \mathrm{C}$ (held for $1 \mathrm{~min}$ ) was ramped at $5{ }^{\circ} \mathrm{C} / \mathrm{min}$ to $300{ }^{\circ} \mathrm{C}$ and held for $5 \mathrm{~min}$. Post-run was $3 \mathrm{~min}$. Total GC-MS runtime was $56 \mathrm{~min}$. The mass spectrometer was operated at EI mode at $70 \mathrm{eV}$. Selected compounds were identified by 
selected ion monitoring (SIM mode). Data was processed using MSD Chemstation-qualitative analysis software (Agilent Technologies).

All the measurement of $\mathrm{pH}$ and Electrical Conductivity (EC) were performed by $\mathrm{pH}$ meter (Eutech 2700) and EC meter (Hach-Company), respectively. BOD were assessed by determining oxygen consumption (respirometric method) using a BOD Trak (Hach). Bicarbonate ions were determined by measurement of the alkalinity of PCW based on Standard methods [45]. Chloride ions were measured by the Mohr method using titration with silver nitrate and potassium chromate as indicator according to Standard methods [45]. $\mathrm{H}_{2} \mathrm{O}_{2}$ was measured by a colorimetric method with titanium (IV) oxysulfate [35]. COD of the treated wastewater was determined using the closed reflux colorimetric method by a HACH (DR6000) spectrophotometer. In all experiments, in order to eliminate the interference of chloride ions, a 20:1 wt ratio of mercury (II) sulfate and chloride ion was adjusted [45]. In the samples collected after CWPO experiments, in order to eliminate the interference of residual $\mathrm{H}_{2} \mathrm{O}_{2}$, the experimental COD (CODexp) and $\mathrm{BOD}_{5}$ $\left(\mathrm{BOD}_{5}\right.$, exp) were corrected as described in Eqs. (4) and (5) (the concentration range of $0 \leq\left[\mathrm{H}_{2} \mathrm{O}_{2}\right]<2000 \mathrm{mg} / \mathrm{L}$ was considered.) [46]. TOC was determined by a Shimadzu (Japan) TOC analyzer. Mineralization and biodegradability studies of the final effluent was investigated using calculation of $\mathrm{BOD}_{5} / \mathrm{COD}$ ratio, values of $\mathrm{AOS}$ and COS. A colorimetric method with 1, 10-phenanthroline was applied to determine the concentration of dissolved iron (II) content in the bulk samples, by a HACH spectrophotometer (DR6000) with absorbance at $510 \mathrm{~nm}$. The samples withdrawal after CWPO experiments for determination of BPA, COD, TOC, $\mathrm{H}_{2} \mathrm{O}_{2}$ and $\mathrm{BOD}_{5}$ were immediately placed in refrigerator (kept at $4{ }^{\circ} \mathrm{C}$ ) to stop the reaction until the
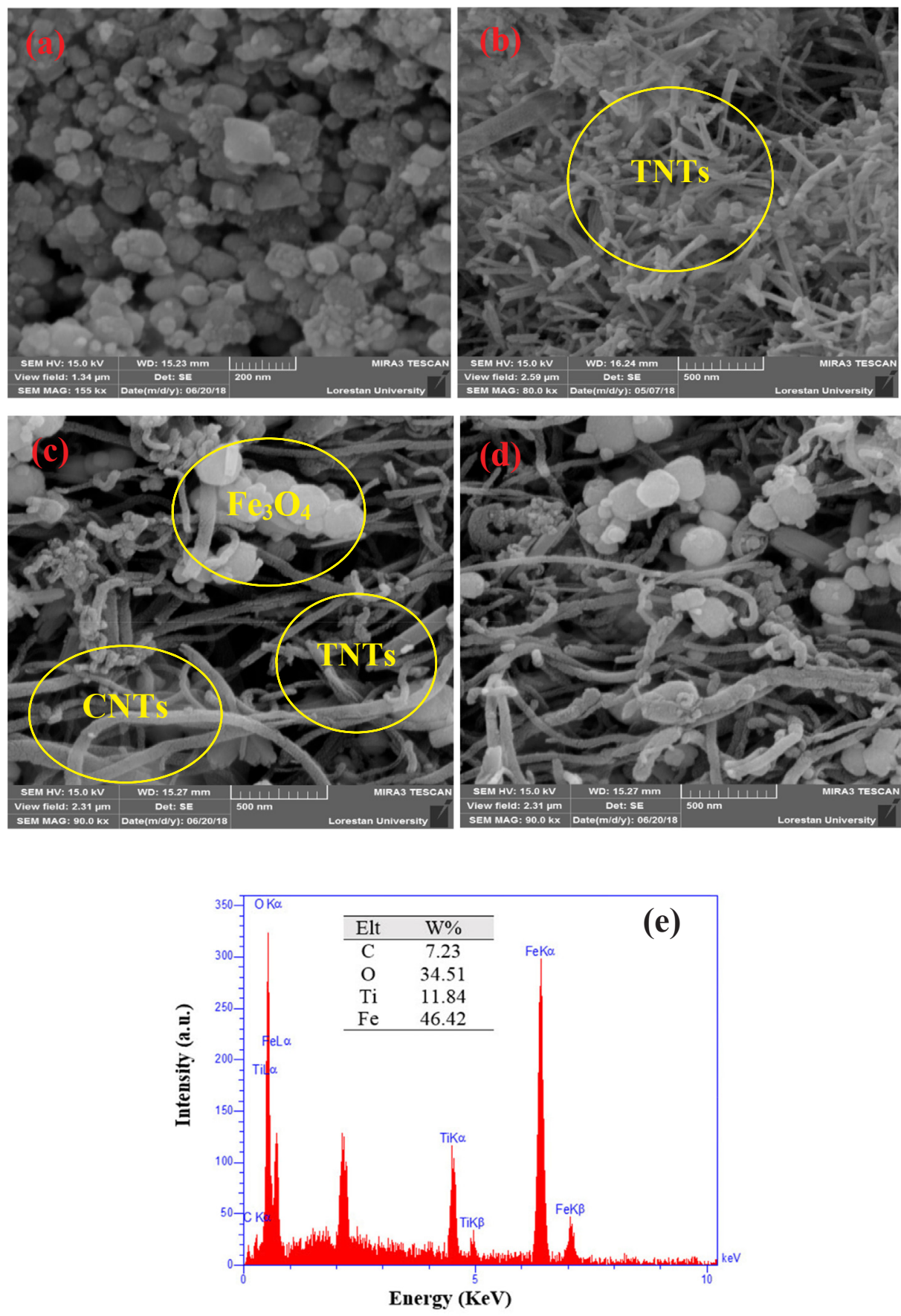

Fig. 2. SEM micrographs of (a) $\mathrm{Fe}_{3} \mathrm{O}_{4}$ MNPs, (b) TNTs, (c), (d) and (e) SEM and corresponding EDX spectra of magnetite TNT/CNT nanocomposite. 
analysis. In all experiments, when necessary, appropriate dilutions for parameters were made.

$$
\begin{aligned}
& \mathrm{BOD}_{5}(\mathrm{mg} / \mathrm{L})=\mathrm{BOD}_{5, \text { exp. }}-0.4706\left[\mathrm{H}_{2} \mathrm{O}_{2}\right] / \mathrm{mg} / \mathrm{L} \\
& \mathrm{COD}(\mathrm{mg} / \mathrm{L})=\mathrm{COD}_{\text {exp. }}-0.4706\left[\mathrm{H}_{2} \mathrm{O}_{2}\right] / \mathrm{mg} / \mathrm{L}
\end{aligned}
$$

\section{Results and discussion}

\subsection{Characterization of the synthesized magnetite TNT/CNT nanocomposite}

The morphologies of the prepared $\mathrm{Fe}_{3} \mathrm{O}_{4}$ MNPs, TNTs and magnetite TNT/CNT nanocomposite were revealed by SEM, as shown in Fig. 2a-d. With respect to Fig. 2a, it is observed that the $\mathrm{Fe}_{3} \mathrm{O}_{4}$ MNPs have uniform spherical shape with high homogeneity. Due to the magnetic properties of the nanoparticles and their interactions, the agglomeration of $\mathrm{Fe}_{3} \mathrm{O}_{4}$ MNPs may be occurred $[40,47,48]$. As can be seen in Fig. 2a, the average size of the $\mathrm{Fe}_{3} \mathrm{O}_{4}$ MNPs is in the range between 20 and $80 \mathrm{~nm}$, confirming the successful synthesis in a nano range. Fig. $2 \mathrm{~b}$ clearly shows the nanotubular morphology of titanium nanotubes synthesized using the hydrothermal method. Fig. 2c, d. depicts the nanotubular structure of the magnetite TNT/CNT nanocomposite, confirming that the addition of $\mathrm{Fe}_{3} \mathrm{O}_{4}$ and CNTs to the reaction solution for alkaline hydrothermal synthesis treatment did not damage the formation and progress of TNTs. Fig. 2e shows the EDX analysis of the magnetite TNT/CNT nanocomposite catalyst, confirming the presence of peaks assigned to $\mathrm{C}, \mathrm{O}, \mathrm{Fe}$ and $\mathrm{Ti}$ in the structure of the as-prepared catalyst.

In order to determine the crystalline structure of the nanocomposite, $\mathrm{XRD}$ analysis was performed in the 2 Theta range between 10 and $80^{\circ}$ at $25^{\circ} \mathrm{C}(\lambda=1.54 \AA)$. As shown in Fig. 3 for the $\mathrm{Fe}_{3} \mathrm{O}_{4}$ XRD pattern, six relative intense peaks at angles of $2 \theta$ of $30.07^{\circ}, 35.44^{\circ}, 43.15^{\circ}, 56.6^{\circ}$, $56.99^{\circ}$ and $62.6^{\circ}$ were attributed to the diffraction of cubic phase of the orthorhombic magnetite, corresponding to indices (220), (311), (4 0 0), (4 22 2), (5 11 ) and (4 4 0), respectively [1,49]. According to the XRD pattern of $\mathrm{Fe}_{3} \mathrm{O}_{4}$, the relative position and intensity of all peaks were in good agreement with the standard $\mathrm{Fe}_{3} \mathrm{O}_{4}$ diffraction data (JCPDS, Card No. 01-1111). A broad diffraction peak at $2 \theta=26.2^{\circ}$ $\left(\begin{array}{lll}0 & 0 & 2\end{array}\right)$ and $42.8^{\circ}\left(\begin{array}{lll}1 & 0 & 0\end{array}\right)$ was observed for CNTs in Fig. 3, which can be attributed to the characteristic reflection of amorphous graphitic nature of CNTs (JCPDS, Card No. 08-0415), which corroborates the cylindrical concentric tubular structure of CNTs and the $\mathrm{sp}^{2}$ hybridization of the carbon atoms $[36,38]$. According to JCPDS card No. 71-1166 for TNTs, as shown in Fig. 3, TNTs shows intense peaks at $2 \theta$ values of $25.3^{\circ}$

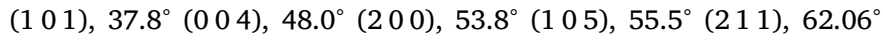
(2 04$), 70.02^{\circ}(220)$ and $75.9^{\circ}(215)$. These patterns are attributed to pure $\mathrm{TiO}_{2}$ anatase phase, which confirmed that its phase was used for TNTs synthesis [38]. As shown in Fig. 3, all diffraction peaks corresponding to CNTs, TNTs, and $\mathrm{Fe}_{3} \mathrm{O}_{4}$ were observed in the X-ray diffractogram of the magnetite TNT/CNT nanocomposite without significant changes in the basic of their diffraction peaks, demonstrating the excellent crystallization degree of the as-synthesized nanocomposite. These results confirmed that the crystal structure of $\mathrm{TiO}_{2}$ was not destroyed by addition of $\mathrm{CNT}$ and $\mathrm{Fe}_{3} \mathrm{O}_{4}$ MNPs during the synthesis reaction and that the TNT formation was successfully achieved. It is important to note that in Fig. 3, due to the overlapping of the CNT diffraction peak at $26.2^{\circ}$ with the diffraction peaks of anatase TNT at $25.3^{\circ}$, there is no obvious reflection attributed to CNTs. On the other hand, this phenomena may be due to the fact that CNTs were homogenously dispersed on the TNTs. These reasons prevents the identification of CNTs diffraction peaks at the magnetite TNT/CNT nanocomposite in Fig. 3 and the reference peaks. Similar findings have been reported in the synthesis of TNT/CNT nanocomposites [38,50].

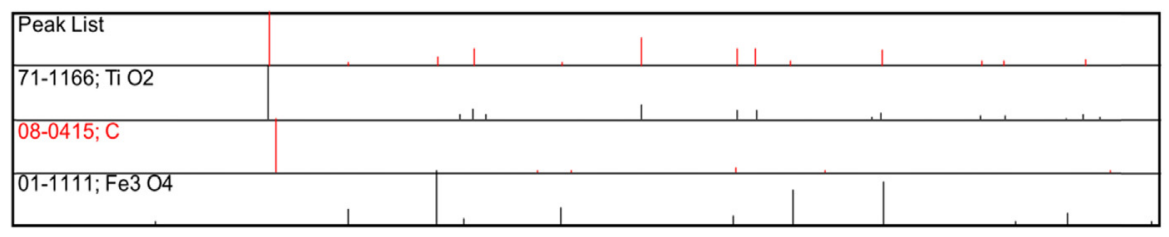

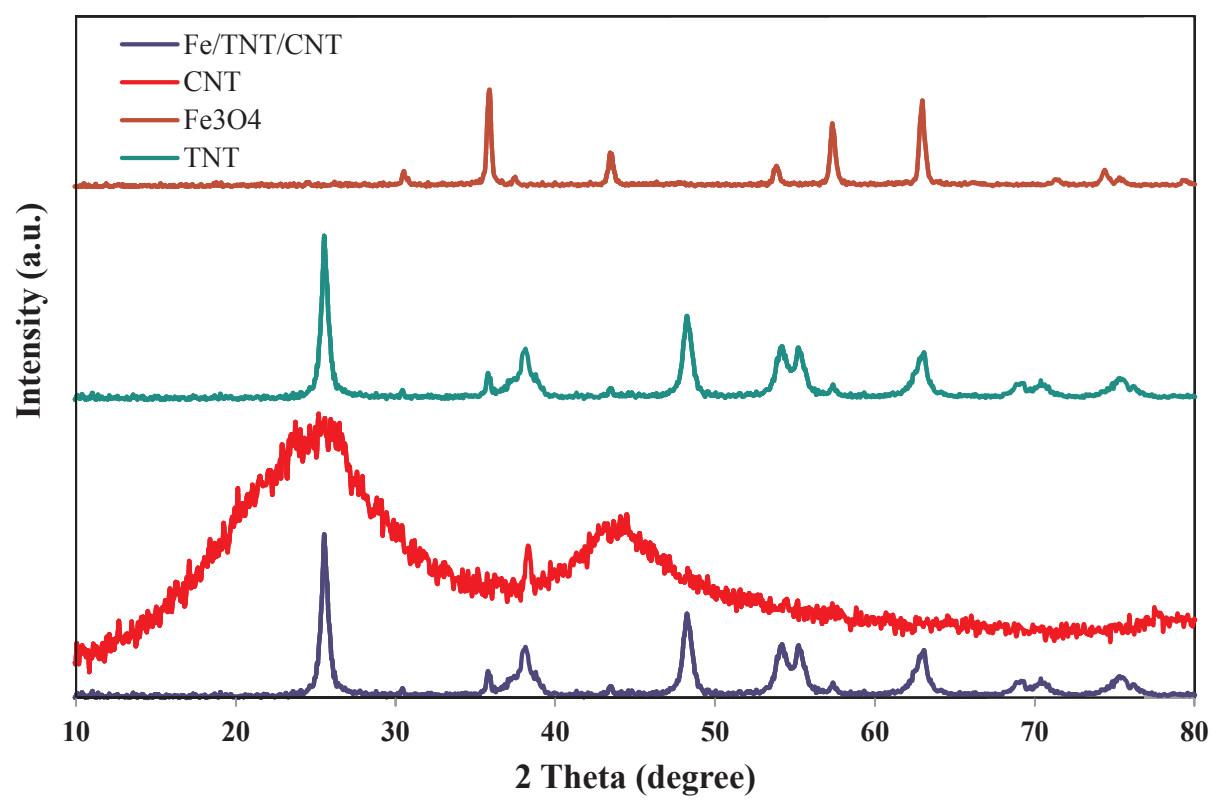

Fig. 3. XRD diffraction pattern of $\mathrm{Fe}_{3} \mathrm{O}_{4}$ MNPs, CNTs, TNTs and the magnetite TNT/CNT nanocomposite. The standard reference pattern of magnetite (crystallography open database code: 01-1111), CNT (crystallography open database code: 08-0415) and TNT (crystallography open database code: 71-1166) are given. 
The FT-IR spectra of the functional groups on the surface of the magnetite TNT/CNT nanocomposite is depicted in Fig. 4a. As shown in this figure, vibration bands were observed at 466, 572, 703, 877, 1094, 1256, 1436, 1643, 1726, 1798, 2854, 2925, 3433, 3758 and $3829 \mathrm{~cm}^{-1}$. The bands around 1726 and $1440 \mathrm{~cm}^{-1}$ were attributed to the $\mathrm{C}=\mathrm{O}$ stretching mode in the carboxylic acid group and in the quinone group, respectively. The band at $580 \mathrm{~cm}^{-1}$ was attributed to the Fe-O group on the surface of the nanocomposite. The band around $1726 \mathrm{~cm}^{-1}$ was attributed to the stretching vibrations of the carboxyl, aldehyde and acid anhydride carbonyl groups $(-\mathrm{C}=\mathrm{O})$ and the bands at $1094-1256 \mathrm{~cm}^{-1}$ were attributed to the $-\mathrm{C}-\mathrm{O}$ stretching vibration. These peaks reveal that the acidic treatment was effective in the introduction of the $-\mathrm{COOH}$ group on the surface of CNTs. These surface functional groups were involved in the interaction between CNT and TNT. The vibration band at $400-600 \mathrm{~cm}^{-1}$ corresponds to the stretching vibration of the $\mathrm{Ti}-\mathrm{O}-\mathrm{Ti}$ bond. In addition, these vibrations in the surface of the nanocomposite were attributed to the bending vibration of $\mathrm{Ti}-\mathrm{O}-\mathrm{C}$ bonds. Therefore, the presence of $\mathrm{Ti}-\mathrm{O}-\mathrm{C}$ bonds in the as-prepared nanocomposite may lead to an increase of its catalytic activity. The strong intense vibration bands at 3433 and $1643 \mathrm{~cm}^{-1}$ correspond to the stretching and deformation vibrations of Ti-OH groups and surface-adsorbed water molecules [38,51]. The FT-IR spectroscopy clearly reveals that the magnetite TNT/CNT nanocomposite was successfully synthesized.

The textural characterization of the magnetite TNT/CNT nanocomposite was carried out by analysis of $\mathrm{N}_{2}$ adsorption. The $\mathrm{N}_{2}$ adsorption/desorption isotherm at $77 \mathrm{~K}$ and pore size distribution of the nanocomposite are depicted in Fig. S1. The specific surface area of the as-prepared nanocomposite, determined using the BET method was $574.1 \mathrm{~m}^{2} / \mathrm{g}$ while its average pore diameter and total pore volume (p/ $\mathrm{p}_{0}=0.990$ ) were $4.75 \mathrm{~nm}$ and $0.68 \mathrm{~cm}^{3} / \mathrm{g}$, respectively. Therefore, the high BET surface area and small pore size of the as-synthesized nanocomposite was related to its porous structure which is favorable to increase its catalytic activity. In addition, this high BET surface area can be attributed to the higher porosity and availability to active sites due to partial dissociation of TNT and/or CNT structure during the functionalization process. As can be seen in Fig. 2, the nanotubular morphology of the TNT and CNT was intact after the surface functionalization.

The VSM magnetization curves of $\mathrm{Fe}_{3} \mathrm{O}_{4}$ MNPs and of magnetite TNT/CNT nanocomposite is shown in Fig. 4b. The magnetic field test in the range of -12 to $+12 \mathrm{kOe}$ was applied to investigate the magnetic properties of the $\mathrm{Fe}_{3} \mathrm{O}_{4}$ MNPs and the nanocomposite. As can be seen, the magnetization saturation of pure $\mathrm{Fe}_{3} \mathrm{O}_{4}$ MNPs was much greater than that of the as-synthesized nanocomposite. Based on the VSM magnetization analysis, the magnetization saturation for pure $\mathrm{Fe}_{3} \mathrm{O}_{4}$ MNPs and magnetite TNT/CNT nanocomposite were 71.71 and $25.55 \mathrm{emu} / \mathrm{g}$, respectively. These results mean that both saturation magnetization values of the catalysts are much higher than the value of $16.3 \mathrm{emu} / \mathrm{g}$, found as enough for magnetic separation from aqueous solution using a magnet [52]. The saturation magnetization values of the catalysts show excellent magnetic potentials, thus they could be easily separated from the aqueous solutions. Bearing this in mind, this feature reduces significantly the operational costs in real-scale
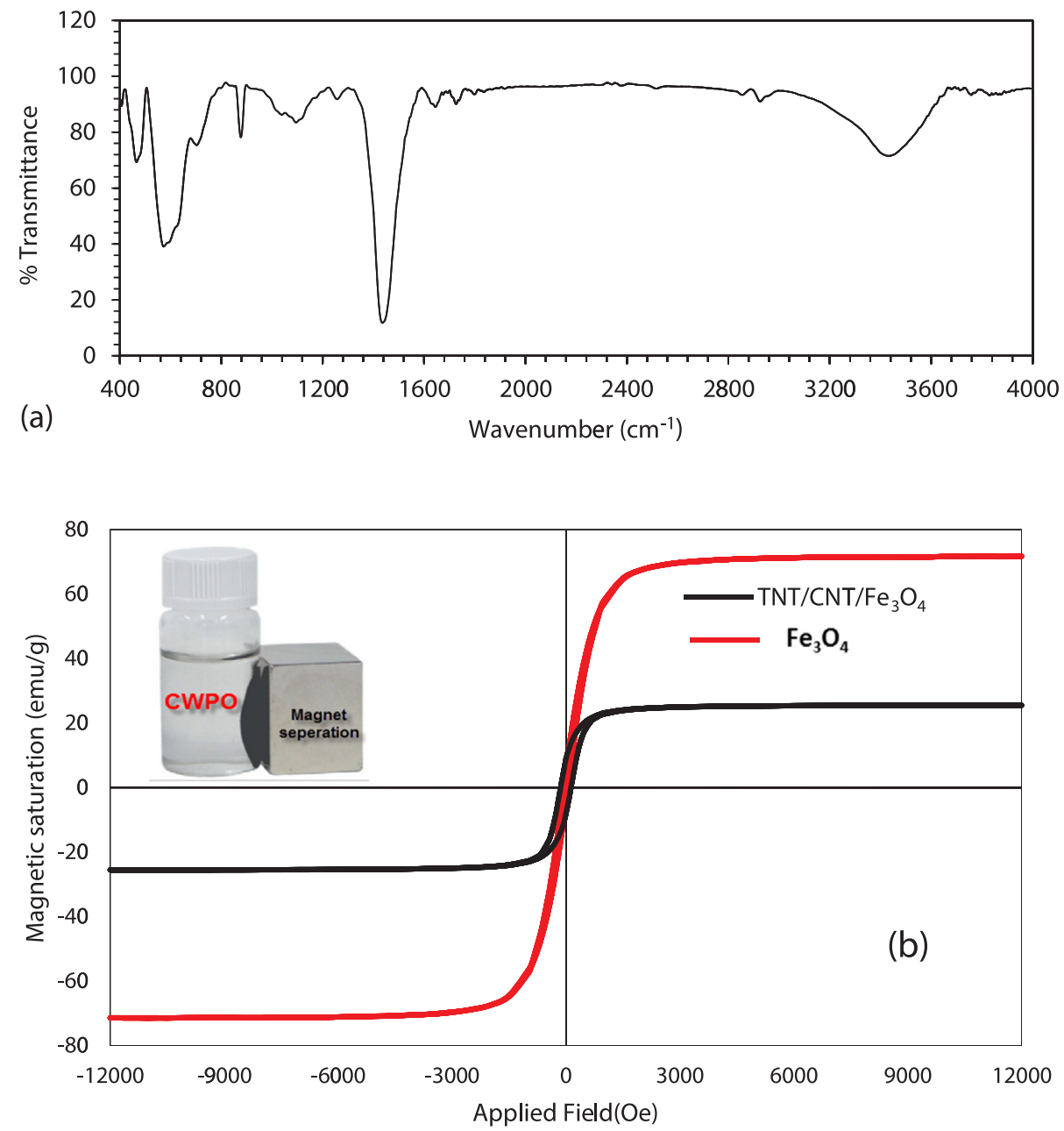

Fig. 4. (a) FT-IR spectra, and (b) Hysteresis loops of $\mathrm{Fe}_{3} \mathrm{O}_{4}$ MNPs and magnetite TNT/CNT nanocomposite (the inset shows a nanocomposite separation from the reaction solution by applying an external magnetic field.). 
applications by using an in-situ magnetic separation procedure. On the other hand, the remarkable variety between the values of the magnetization saturation can be attributed to the presence of the non-magnetic TNT and CNT nanomaterial in the structure of the nanocomposite.

\subsection{CWPO process on BPA degradation in aqueous solution and its degradation mechanism}

In this section, the efficiency of the CWPO process in the presence of the magnetite TNT/CNT nanocomposite was evaluated for the BPA degradation in aqueous solution under the following conditions: [BPA] $0=600 \mathrm{mg} / \mathrm{L},\left[\mathrm{H}_{2} \mathrm{O}_{2}\right]_{\text {stoichiometric }}=3.21 \mathrm{~g} / \mathrm{L}, \mathrm{pH}=3.5, \mathrm{~T}=70^{\circ} \mathrm{C}$ and catalyst loading $=50 \mathrm{mg} / \mathrm{L}$ for $240 \mathrm{~min}$ of reaction time. The obtained results are given in Fig. 5. The pollutant/catalyst mass ratio was kept constant as high as 12 . As can be seen in Fig. 5a, the complete BPA degradation was obtained in the CWPO process after $160 \mathrm{~min}$ of reaction time. In this regard, $63 \%$ of TOC removal was obtained after 240 min of reaction time, confirming that BPA intermediate by-products were not completely degraded under these experimental conditions. The performance of CWPO in terms of non-catalytic and pure adsorption of BPA runs was also performed for evaluation of possible effects of these experiments. As shown in Fig. 5a, the results of noncatalytic experiments in the BPA degradation was negligible after 240 min of reaction time when compared to that achieved by the magnetite TNT/CNT nanocomposite. The efficiency of pure adsorption of BPA obtained with the nanocomposite is $<4 \%$ and can be ascribed to the very low nanocomposite dosage when compared to the BPA concentration used in the experiments (pollutant/nanocomposite mass ratio was 12) [21,53]. Therefore, it can be concluded that the CWPO process using the magnetite TNT/CNT nanocomposite reveals high catalytic activity with complete BPA degradation and $63 \%$ of TOC removal after $240 \mathrm{~min}$ of reaction time. The catalytic performance of CWPO using the magnetite TNT/CNT nanocomposite catalyst was compared with individual, binary and ternary systems in terms of BPA degradation in aqueous solution in the same conditions. Fig. 5b illustrates the BPA removal in different processes under the same conditions. As observed, the magnetite TNT/CNT nanocomposite had the maximum catalytic performance in BPA degradation by CWPO. In the CWPO using CNTs $/ \mathrm{Fe}_{3} \mathrm{O}_{4}$ and TNTs $/ \mathrm{Fe}_{3} \mathrm{O}_{4}$ catalysts, BPA removal was relatively high, $75 \%$ and $67 \%$, respectively at $240 \mathrm{~min}$ reaction time. In the individual systems including CNTs, TNTs and $\mathrm{Fe}_{3} \mathrm{O}_{4}$, the catalysts show relatively low efficiency $(<50 \%)$ in the CWPO in terms of BPA removal. The efficiency of BPA degradation in the process was also investigated in the presence of $\mathrm{H}_{2} \mathrm{O}_{2}$ without any catalyst. As can be seen at Fig. 5b, the ability of $\mathrm{H}_{2} \mathrm{O}_{2}$ to remove BPA without catalyst was low $(<25 \%)$.

In the destructive CWPO mechanism, Fe species used to catalyze hydrogen peroxide decomposition to generate reactive $\mathrm{HO}^{*}$ free radicals. In this regard, based on Eqs. (6) and (7), ferric ions react with $\mathrm{H}_{2} \mathrm{O}_{2}$ and $\mathrm{HO}^{\circ}$ free radicals and ferrous ions were produced. In the next step, ferrous ions are converted to ferric ions via generation of hydroperoxyl radicals $\left(\mathrm{HO}_{2}{ }^{\circ}\right)$. It should be note that in the present work, these reactions in CWPO process may took place both at the catalyst surface and in solution. On the other hand, the magnetite TNT/CNT nanocomposite catalyst provided advantages of two nanotubular structures as well as higher defects on the surface of the nanocomposite when compared to the other materials. Therefore, the higher defects on the surface of the nanocomposite provided more active sites to decomposition of $\mathrm{H}_{2} \mathrm{O}_{2}$ to generate hydroxyl radicals which could enhance the efficiency of organic pollutants degradation.

$\mathrm{Fe}^{2+}+\mathrm{H}_{2} \mathrm{O}_{2} \rightarrow \mathrm{Fe}^{3+}+\mathrm{HO}+\mathrm{HO}^{-}$

$\mathrm{Fe}^{3+}+\mathrm{e}^{-} \rightarrow \mathrm{Fe}^{2+}$

In order to determine the role of $\mathrm{HO}^{-}$radicals in the reaction mechanism of the CWPO process, the scavenging experiment was performed by indirect analysis using tert-butanol (tBuOH) as a specific and strong $\mathrm{HO}^{*}$ scavenger $[1,21]$. For this propose, the BPA degradation in the aqueous solution by CWPO was evaluated by addition of $\mathrm{tBuOH}$ as scavenging agent. Fig. $5 \mathrm{c}$ illustrates the CWPO runs in the presence and absence of $\mathrm{tBuOH}$. As can be seen in Fig. $5 \mathrm{c}$, the BPA degradation is largely decreased in the presence of $\mathrm{tBuOH}$. Therefore, the BPA degradation can be attributed to the reaction mechanism involving the attack of the $\mathrm{HO}^{\circ}$ radicals formed during the CWPO process. As it is confirmed by qualitative GC/MS analysis, the attack of $\mathrm{HO}^{\circ}$ radicals to BPA and to other phenolic compounds in the PCW leads to the openings of the aromatic ring and the series of intermediate by-products and low
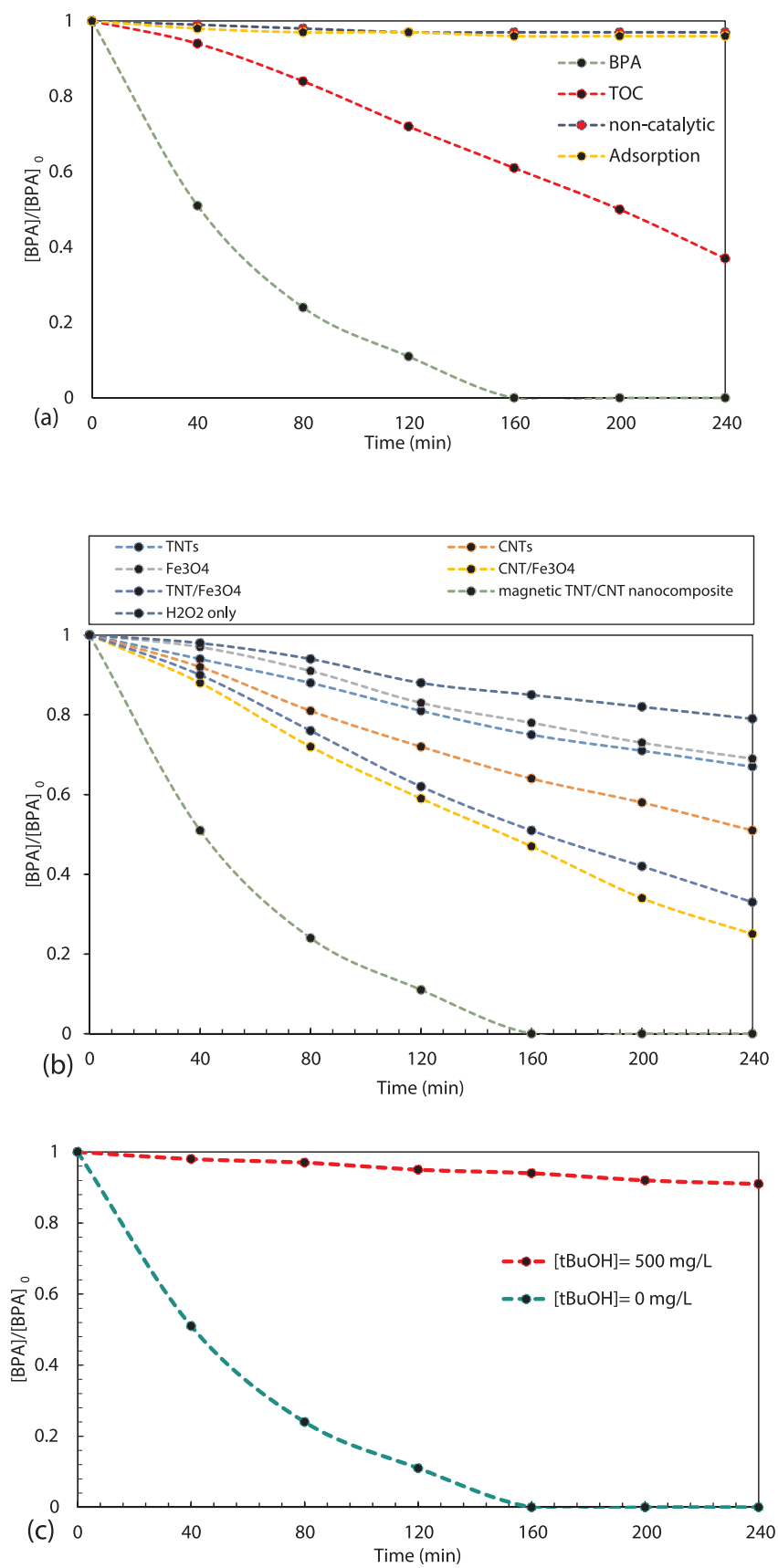

Fig. 5. CWPO of BPA using the magnetite TNT/CNT nanocomposite (a) BPA and TOC degradation (in aqueous solution) (b) comparison between catalytic performance of different catalysts in CWPO (c) effects of the presence of $\mathrm{tBuOH}$ in the BPA degradation. Experiments conducted under the conditions: [BPA] $0=600 \mathrm{mg} / \mathrm{L},\left[\mathrm{H}_{2} \mathrm{O}_{2}\right]$ stoichiometric $=3.21 \mathrm{~g} / \mathrm{L}, \mathrm{pH}=3.5, \mathrm{~T}=70^{\circ} \mathrm{C}$, catalyst loading $=50 \mathrm{mg} / \mathrm{L}$. 
molecular weight carboxylic acids were produced (Fig. 9) [23-54]. It is reported that BPA degradation in AOPs technologies, such as in the CWPO process, may proceed through different mechanisms, including $\mathrm{CO}_{2}$ elimination, dihydroxylation, cleavage of $\mathrm{C}-\mathrm{C}$ bond, $\mathrm{OH}$ group addition and oxidation mechanism [2,55]. Fig. 6 illustrates a mechanism scheme for pollutants degradation and generation of free radicals.

\subsection{The influence of individual operating parameters for CWPO optimization on BPA degradation in the PCW}

Solution $\mathrm{pH}$ plays a key role in the degradation of contaminants in all chemical oxidation processes. Additionally, the solution $\mathrm{pH}$ has an important effect on the conversion of $\mathrm{Fe}^{2+}$ to $\mathrm{Fe}^{3+}$ in solution. The presence of different compounds in real industrial wastewaters, such as in PCW, can be influential on catalytic oxidation processes. Among different compounds, anions such as bicarbonates and chlorides are considered well-known free radicals scavengers [56].

The bicarbonate ion along with carbonate ions are also considered free radical scavengers in chemical oxidation processes. Since the bicarbonate equilibrium concentration in water/wastewater depends on $\mathrm{pH}$, according to the acid ionization reactions and corresponding acid dissociation constants described in Eqs. (8) and (9), the bicarbonate ion is the predominant species in $\mathrm{pH}<8.3$, thus effectively quenching the free radicals and producing carbonate $\left(\mathrm{CO}_{3}{ }^{-}\right)$and bicarbonate $\left(\mathrm{HCO}_{3}{ }^{-}\right)$) radicals with lower redox potential $\left(\mathrm{E}^{0}=1.78 \mathrm{~V}\right)$ than $\mathrm{HO} \cdot$ radicals. Additionally, the rate constants of the reactions between $\mathrm{HO}^{*}$ radicals with organic compounds are 2-3 times higher than that of $\mathrm{CO}_{3}{ }^{-}{ }^{-}$with organic matter. Moreover, $\mathrm{HCO}_{3}{ }^{-}$could increase the initial $\mathrm{pH}$ value and reduce the oxidation potential of the free radicals. At the natural $\mathrm{pH}$ of the PCW $(\mathrm{pH}=8.6)$, the dominant species is the bicarbonate ion $\left(\mathrm{HCO}_{3}{ }^{-}\right)$and thus negatively affecting the performance of CWPO, due to the $\mathrm{HO}^{-}$radical scavenging based on Eq. (6) as well as to the direct decomposition of $\mathrm{H}_{2} \mathrm{O}_{2}$ through the parasitic reaction described in Eq. (13). It should be noted that decreasing the solution $\mathrm{pH}$ to values below 6.35 could prevent this parasitic reaction and lead to the conversion of $\mathrm{HCO}_{3}{ }^{-}$to carbonic acid $\left(\mathrm{H}_{2} \mathrm{CO}_{3}\right)$. In the next step, as described by Eq. (14), $\mathrm{H}_{2} \mathrm{CO}_{3}$ decomposed into water and carbon dioxide (then $\mathrm{CO}_{2}$ goes to gas phase) $[21,56,57]$. Therefore, it expected that the performance of CWPO at $\mathrm{pH}<6.35$ will favour the degradation of BPA present in PCW, in order to overcome the interference of bicarbonate species $(10345 \mathrm{mg} / \mathrm{L})$.

The PCW is characterized by high salinity, with high concentration of chloride ions (14395 mg/L). Chloride ions shows both inhibitory and promotional effects due to the severe tendency of chloride to scavenge free radical species and to produce reactive chlorine species $\left(\mathrm{Cl}^{\circ}, \mathrm{Cl}_{2}{ }^{-}-\right.$, $\mathrm{HOCl}^{-}-$and $\mathrm{Cl}_{2}$ ) with lower reactivity. It is reported that, as described by Eq. (9), the HO radical scavenging reaction by chloride ion is dependent on the solution $\mathrm{pH}$. The chlorine ion $\left(\mathrm{Cl}^{-}\right)$and its transient form, the hypochlorous radical $\left(\mathrm{HOCl}^{-}\right.$) (rate constant
$6.1 \times 10^{9} \mathrm{~s}^{-1}$ ), are converted together in the series of reactions described in Eqs. (9) and (10). The chlorine ion $\left(\mathrm{Cl}^{-}\right)$, due to its high reaction rate constant $\left(4.3 \times 10^{9} \mathrm{M}^{-1} \mathrm{~s}^{-1}\right)$, efficiently scavenge $\mathrm{HO}$. radicals. The hypochlorous radical can also be converted to $\mathrm{Cl}^{\circ}$ and $\mathrm{H}_{2} \mathrm{O}$ via a protonation reaction (rate constant of $2.1 \times 10^{10} \mathrm{~L} \mathrm{~mol}^{-1} \mathrm{~s}^{-1}$ ); however the reverse reaction rate $\left(1.3 \times 10^{3} \mathrm{~s}^{-1}\right)$ is much smaller. Therefore, as described in Eq. (10), when the solution pH decreases, the formation of the chlorine radical $\left(\mathrm{Cl}^{\circ}\right)$ increases by the protonation reaction, thus increasing the $\mathrm{HO}^{\circ}$ radical scavenging effect (by Eq. (9)). Therefore, the pKa of the deprotonation reaction is the important point to determine the extent of $\mathrm{HO}^{\circ}$ radical scavenging and it can be concluded that chlorine radical becomes the dominant species at solution $\mathrm{pH}<7.2$ and, in the opposite, at $\mathrm{pH}>7.2$, the hypochlorous radical becomes the dominant species and resulted in the reduction of $\mathrm{HO}^{\text {. }}$ radical scavenging (Eq. (9)) [21,56,57]. Therefore, with regard to the high concentration of chloride species $(14395 \mathrm{mg} / \mathrm{L})$ present in the PCW considered in present study, it is expected that the operation of CWPO at $\mathrm{pH}>7.2$ could be appropriate for degradation of BPA as well as COD and TOC of the polycarbonate wastewater.

$\mathrm{HCO}_{3}^{-}+\mathrm{HO} \cdot \mathrm{CO}_{3}^{--}+\mathrm{H}_{2} \mathrm{O}$

$\mathrm{Cl}^{-}+\mathrm{HO} \cdot \mathrm{HOCl}^{-}$

$\mathrm{HOCl}^{-}+\mathrm{H}^{+} \mathrm{Cl} \cdot+\mathrm{H} 2 \mathrm{O} \quad$ pka $=7.2$

$\mathrm{H}_{2} \mathrm{CO}_{3}(\mathrm{aq}) \mathrm{H}+(\mathrm{aq})+\mathrm{HCO}_{3}^{-}(\mathrm{aq}) \quad \mathrm{pK}_{\mathrm{a} 1}=6.35$

$\mathrm{HCO}_{3}^{-}(\mathrm{aq}) \mathrm{H}+(\mathrm{aq})+\mathrm{CO}_{3}^{-}(\mathrm{aq}) \quad \mathrm{pK}_{\mathrm{a} 2}=10.33$

$\mathrm{HCO}_{3}^{-}(\mathrm{aq})+\mathrm{H}_{2} \mathrm{O}_{2} \mathrm{HCO}_{4}^{-}(\mathrm{aq})+\mathrm{H}_{2} \mathrm{O}(\mathrm{aq})$

$\mathrm{H}_{2} \mathrm{CO}_{3}(\mathrm{aq}) \mathrm{CO}_{2}(\mathrm{~g})+\mathrm{H}_{2} \mathrm{O}(\mathrm{l})$

Considering the significant role of the operating solution $\mathrm{pH}$ in the efficiency of CWPO for BPA degradation present in the PCW, the determination of the optimum operating $\mathrm{pH}$ in the CWPO process was assessed as the first individual parameter in the range 2.5-8.6 (the natural $\mathrm{pH}$ of PCW was 8.6). This range of $\mathrm{pH}$ was chosen to decrease the negative effects of bicarbonates and chlorides, which solution $\mathrm{pH}$ should be $\mathrm{pH}<6.35$ and $\mathrm{pH}>7.2$, respectively.

The influence of solution $\mathrm{pH}$ in six levels (in the range 2.5-8.6) in the degradation of BPA present in PCW by CWPO process was evaluated under the conditions of $\left[\mathrm{H}_{2} \mathrm{O}_{2}\right]_{0}=2.5 \mathrm{~g} / \mathrm{L}, \mathrm{T}=50{ }^{\circ} \mathrm{C}$ and magnetic $\mathrm{TNT} / \mathrm{CNT}$ catalyst load $=75 \mathrm{mg} / \mathrm{L}$ for $240 \mathrm{~min}$ reaction time. The obtained results are given in Fig. 7a. As can be observed, the performance of the CWPO process in terms of BPA degradation shows an increasing trend as the solution $\mathrm{pH}$ increases from 2 to 6.30. In the opposite, its efficiency was greatly suppressed when $\mathrm{pH}$ was higher than 6.30 . This behavior could be attributed to the presence of high concentration of bicarbonates and chlorides in the PCW, which affected the CWPO process in the different solution $\mathrm{pH}$. It is worth to note that at $\mathrm{pH}>$ $6,>95 \%$ of the initial concentration of $\mathrm{H}_{2} \mathrm{O}_{2}$ in the solution was

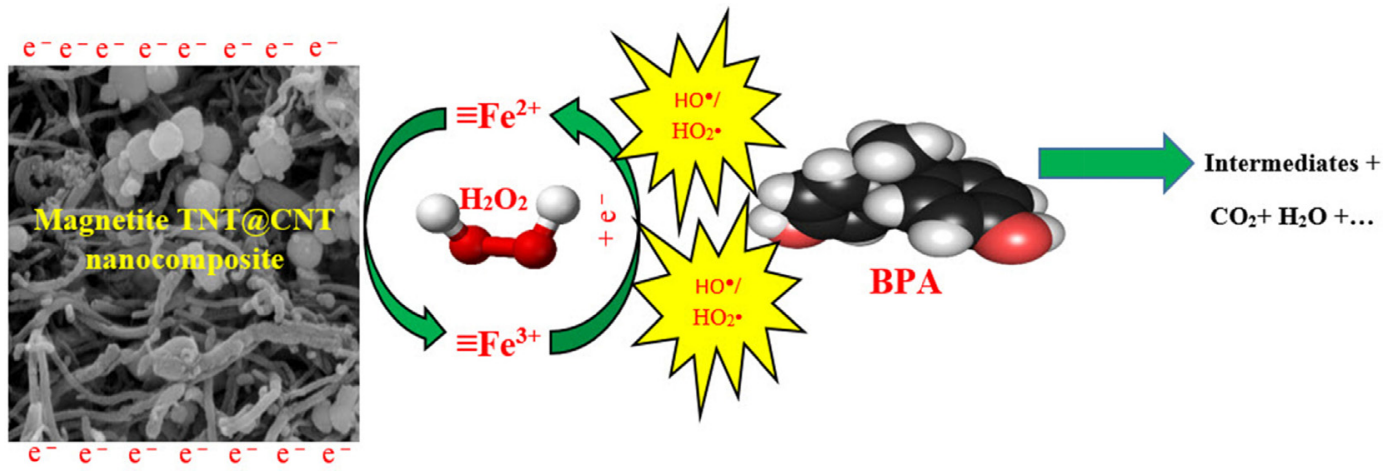

Fig. 6. Schematic diagram of the proposed mechanism illustrating the generation of free radicals and the organic pollutants degradation. 

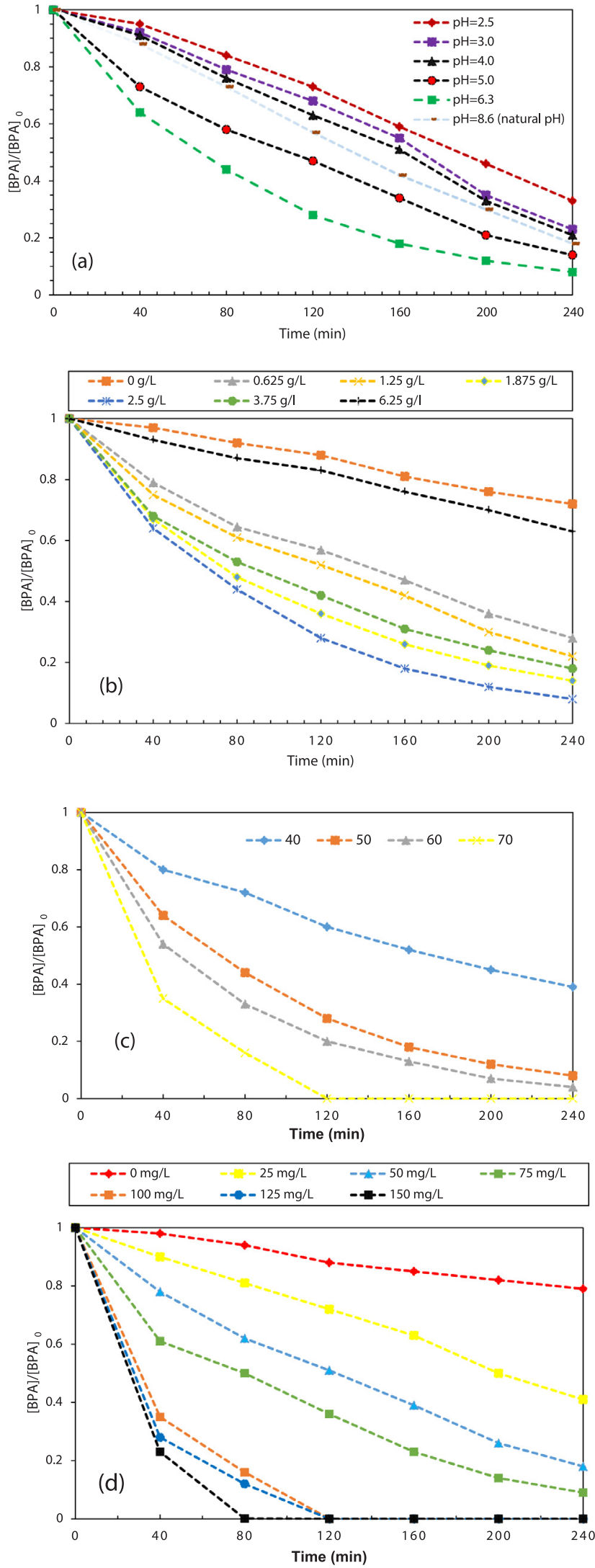

Fig. 7. Influencing parameters in the CWPO experiments performed with the magnetite TNT/CNT nanocomposite on the removal of BPA $(50 \mathrm{mg} / \mathrm{L})$ in the PCW (a) solution $\mathrm{pH}_{0} \quad\left(\left[\mathrm{H}_{2} \mathrm{O}_{2}\right]_{0}=2.5 \mathrm{~g} / \mathrm{L}, \quad \mathrm{T}=50^{\circ} \mathrm{C}\right.$ and catalyst load $=75 \mathrm{mg} / \mathrm{L}) \quad$ (b) $\mathrm{H}_{2} \mathrm{O}_{2}$ dosage $\left(\mathrm{pH}=6.30, \quad \mathrm{~T}=50{ }^{\circ} \mathrm{C}\right.$ and catalyst load $=75 \mathrm{mg} / \mathrm{L})$, (c) reaction temperature $\left(\mathrm{pH}=6.30,\left[\mathrm{H}_{2} \mathrm{O}_{2}\right]_{0}=2.5 \mathrm{~g} / \mathrm{L}\right.$ and catalyst load $=75 \mathrm{mg} / \mathrm{L}) \quad(\mathrm{d})$ magnetite $\mathrm{TNT} / \mathrm{CNT}$ nanocomposite loading $\left(\mathrm{pH}=6.30,\left[\mathrm{H}_{2} \mathrm{O}_{2}\right]_{0}=2.5 \mathrm{~g} / \mathrm{L}\right.$, and $\left.\mathrm{T}=70{ }^{\circ} \mathrm{C}\right)$.

rapidly consumed, probably due to the parasitic reaction between $\mathrm{HCO}_{3}{ }^{-}$and $\mathrm{H}_{2} \mathrm{O}_{2}$, which is not favored to generate $\mathrm{HO}$ radicals (Eq. (13)). On the other hand, chloride ion has the severe tendency to scavenge free radical species ( $\mathrm{HO}^{\circ}$ radicals), which could be ascribed to decreasing the performance of CWPO at $\mathrm{pH}$ lower than 6.30 (Eq. (9)). Therefore, the solution $\mathrm{pH}$ of 6.30 was selected as the optimum value for subsequent experiments. The rate constants $(\mathrm{k})$ of BPA degradation in the CWPO were obtained using a first order kinetic model and found to be $0.0039,0.005,0.0053,0.0074,0.0106,0.0061 \mathrm{~min}^{-1}$ for initial $\mathrm{pH}$ of $2.5,3.0,4.0,5.0,6.30$ and 8.60 respectively (Fig. 8a).

In order to perform CWPO process optimization, the influence of $\mathrm{H}_{2} \mathrm{O}_{2}$ dosage in BPA degradation in the PCW was investigated in range $0-6.25 \mathrm{~g} / \mathrm{L}$ under the experimental conditions of $\mathrm{pH}=6.3, \mathrm{~T}=50^{\circ} \mathrm{C}$ and catalyst loading of $75 \mathrm{mg} / \mathrm{L}$ for $240 \mathrm{~min}$. The obtained results are depicted in Fig. 7b. Since $\mathrm{H}_{2} \mathrm{O}_{2}$ is responsible for the generation of the $\mathrm{HO}^{-}$radicals that decompose the organic pollutant molecules, its presence is necessary to start CWPO processes. In this sense, the use of excess amount of $\mathrm{H}_{2} \mathrm{O}_{2}$ could be unfavored to generate enough oxidant agents to achieve the required extent of treatment [21-23]. According to Fig. $7 \mathrm{~b}$, the CWPO process efficiency in BPA degradation show increasing trend regarding the $\mathrm{H}_{2} \mathrm{O}_{2}$ dosage and then, decreasing with higher $\mathrm{H}_{2} \mathrm{O}_{2}$ concentrations fed. In this series of CWPO experiments, the maximum BPA degradation was achieved at $2.5 \mathrm{~g} / \mathrm{L} \mathrm{H}_{2} \mathrm{O}_{2}$ concentration (corresponding to 10-fold higher concentration than that the stoichiometric concentration for BPA mineralization in the PCW). The decrease of the BPA degradation in the CWPO process observed when $\mathrm{H}_{2} \mathrm{O}_{2}$ concentration increases above $2.5 \mathrm{~g} / \mathrm{L}$ may be related to the competition between $\mathrm{H}_{2} \mathrm{O}_{2}$ molecules and the organic compounds (herein, BPA and other organic compounds present in the industrial wastewater i.e., PCW) for reaction with the generated hydroxyl and hydroperoxyl $\left(\mathrm{HO}_{2}{ }^{\circ}\right)$ free radicals (based on Eqs. (15) and (16), respectively).

Therefore, when a higher $\mathrm{H}_{2} \mathrm{O}_{2}$ concentration is present in the aqueous solution, the rate of reaction (15) increases, decreasing the concentration of available $\mathrm{HO}^{\circ}$ radicals for reaction (16), thus leading to a decline on the removal rate of BPA. Based on Eq. (17)-(19), the free radicals may react with each other or also react with $\mathrm{H}_{2} \mathrm{O}_{2}$ in a series of parasitic reactions.

$\mathrm{HO}+\mathrm{H}_{2} \mathrm{O}_{2} \rightarrow \mathrm{H}_{2} \mathrm{O}+\mathrm{HO}_{2}$

$\mathrm{HO}+\mathrm{BPA} /$ other organic pollutants $\rightarrow$ intermediate and/or end products

$\mathrm{HO}+\mathrm{HO}_{2} \cdot \rightarrow \mathrm{O}_{2}+\mathrm{H}_{2} \mathrm{O}$

$\mathrm{HO}+\mathrm{HO} \rightarrow \mathrm{H}_{2} \mathrm{O}_{2}$

$\mathrm{HO}_{2}+\mathrm{HO}_{2} \rightarrow \mathrm{H}_{2} \mathrm{O}_{2}+\mathrm{O}_{2}$

Therefore, a high concentration of $\mathrm{H}_{2} \mathrm{O}_{2}$ does not necessarily results in a higher organic pollutant removal in CWPO, and the consumption of an excess of oxidant is often useless in the reaction. On the other hand, regarding this mechanism, the competition of $\mathrm{H}_{2} \mathrm{O}_{2}$ molecules with the organic matter molecules for adsorption on the active sites on the magnetite TNT/CNT nanocomposite surface also diminishes the removal of BPA, however it is considered a negligible way for contaminant removal. The rate constants $(\mathrm{k})$ of BPA degradation in the CWPO were obtained using a first order kinetic model and found to be $0.057,0.203,0.241,0.322,0.422,0.277,0.074 \mathrm{~min}^{-1}$ for $\mathrm{H}_{2} \mathrm{O}_{2}$ concentrations of $0,0.625,1.25,1.875,2.5,3.75$ and $6.25 \mathrm{~g} / \mathrm{L}$, respectively 

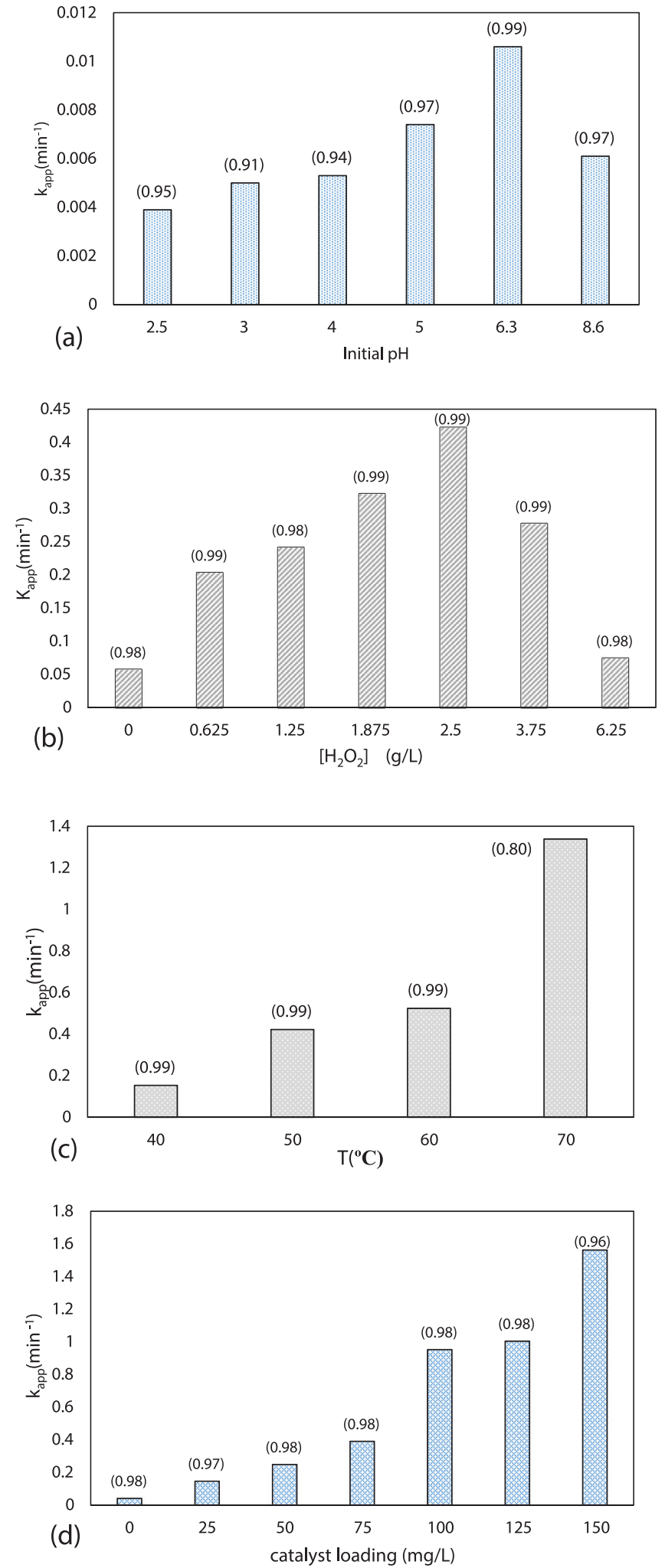

Fig. 8. Apparent first order reaction rate constants $\left(k_{\text {app }}\right)$ obtained in CWPO experiments performed on the removal of BPA in the PCW under different (a) initial $\mathrm{pH}$ (b) $\mathrm{H}_{2} \mathrm{O}_{2}$ dosage (c) reaction temperature (d) catalyst loading. (The numbers in brackets represent the regression coefficients of the linear fitting $\left(\mathrm{R}^{2}\right)$ ).

\section{(Fig. 8b).}

The reaction temperature is another important operating parameter in the CWPO process. Therefore, the influence of the reaction temperature in the range of $40-70^{\circ} \mathrm{C}$ in BPA degradation by CWPO was evaluated under the conditions of $\mathrm{pH}=6.30,\left[\mathrm{H}_{2} \mathrm{O}_{2}\right]=2.5 \mathrm{~g} / \mathrm{L}$ and catalyst loading of $75 \mathrm{mg} / \mathrm{L}$ for $240 \mathrm{~min}$ of reaction time, and their results are given in Fig. 7c. As observed, when increasing the reaction temperature from 40 to $70^{\circ} \mathrm{C}$, the BPA degradation in the CWPO process increased substantially. The rate constants $(\mathrm{k})$ of BPA degradation in the CWPO were obtained using a first order kinetic model and found to be $0.153,0.422,0.524,1.339 \mathrm{~min}^{-1}$ for reaction temperatures of 40 , 50, 60 and $70^{\circ} \mathrm{C}$, respectively (Fig. 8c).

In order to better understand the effect of reaction temperature on the reaction rates, the activation energy for BPA degradation during CWPO was calculated by applying Eq. (20) $[11,58]$. For that purpose, the Arrhenius plot (ln k vs 1/T) was used to determine the apparent activation energy (Ea).

$\ln k=\ln A_{0}-\frac{E_{a}}{R} \frac{1}{T}$

where $E_{a}$ is the apparent Arrhenius activation energy $(\mathrm{J} / \mathrm{mol}), A_{0}$ is the Arrhenius factor or the pre-exponential factor (also known frequency factor) $\left(\mathrm{min}^{-1}\right), \mathrm{T}$ is the reaction temperature $(\mathrm{K})$ and $\mathrm{R}$ is the universal gas constant $(8.314 \mathrm{~J} /(\mathrm{mol} \mathrm{K}))$. Based on the Arrhenius plot given in Fig. S2, a value of $\mathrm{Ea}=60.08 \mathrm{~kJ} / \mathrm{mol}$ was obtained, indicating a positive effect of the reaction temperature on the BPA degradation by CWPO. Therefore, the optimal reaction temperature was selected as $70{ }^{\circ} \mathrm{C}$ for subsequent experiments.

The catalyst dosage is an important parameter in CWPO optimization due to its key role in the generation of $\mathrm{HO}^{\circ}$ radicals, in the enhancement of the catalytic activity for degradation of BPA and in the treatment of PCW in terms of COD and TOC. Therefore, CWPO runs were carried out considering nanocomposite loads of 0-150 mg/L under conditions of solution $\mathrm{pH}=6.3,\left[\mathrm{H}_{2} \mathrm{O}_{2}\right]=2.5 \mathrm{~g} / \mathrm{L}$ and $\mathrm{T}=70{ }^{\circ} \mathrm{C}$ for $240 \mathrm{~min}$ of reaction time. The results obtained are presented in Fig. $7 \mathrm{~d}$ and show that increasing the nanocomposite dosage in the CWPO process, the BPA degradation increases significantly. Under these experimental conditions, increasing the catalyst dosage from 25 to $150 \mathrm{mg} / \mathrm{L}$, the reaction rate constants also increased from 0.146 to $1.562 \mathrm{~min}^{-1}$, respectively (Fig. 8d). Therefore, it can be concluded that the performance of CWPO in the presence of the nanocomposite was increased substantially, which can be ascribed to the increase of the number of active sites for enhancing the decomposition rate of $\mathrm{H}_{2} \mathrm{O}_{2}$ molecules and subsequently the generation of more free radical $\left(\mathrm{HO}^{*}\right.$ radicals) as well as the availability of high pollutants in the PCW and oxidant molecules increases the chance for their interaction on the surface of the nanocomposite. It should be noted that at $100 \mathrm{mg} / \mathrm{L}$ and higher nanocomposite dosage, the complete BPA degradation was obtained in the CWPO process. Therefore, a catalyst dosage of $100 \mathrm{mg} / \mathrm{L}$ was chosen for further experiments, in which the complete BPA degradation was obtained in 120 min of reaction time.

\subsection{The stability and reusability of the nanocomposite}

The stability and reusability of a catalyst is also one of the most important parameters especially regarding the industrial or its realscale applications, such as in the PCW treatment point of view. Therefore, after the optimization performed on the CWPO operating parameters, the stability and reusability of the magnetite TNT/CNT nanocomposite were assessed by four consecutive runs. For that purpose, after each CWPO run, the nanocomposite was separated using the external magnet, washed several times with deionized water and dried at $80{ }^{\circ} \mathrm{C}$ for $2 \mathrm{~h}$ and used in the next CWPO run with fresh PCW. The obtained results are given in Fig. 9. As observed, under the optimum experimental conditions, the BPA and $\mathrm{H}_{2} \mathrm{O}_{2}$ conversions obtained in each successive CWPO run after 240 min have only a slight decline ( $<10 \%$ reduction), confirming the high catalytic activity and stability of the catalyst in the CWPO process, thus showing high potential for the real-scale industrial PCW wastewater treatment considered in this 


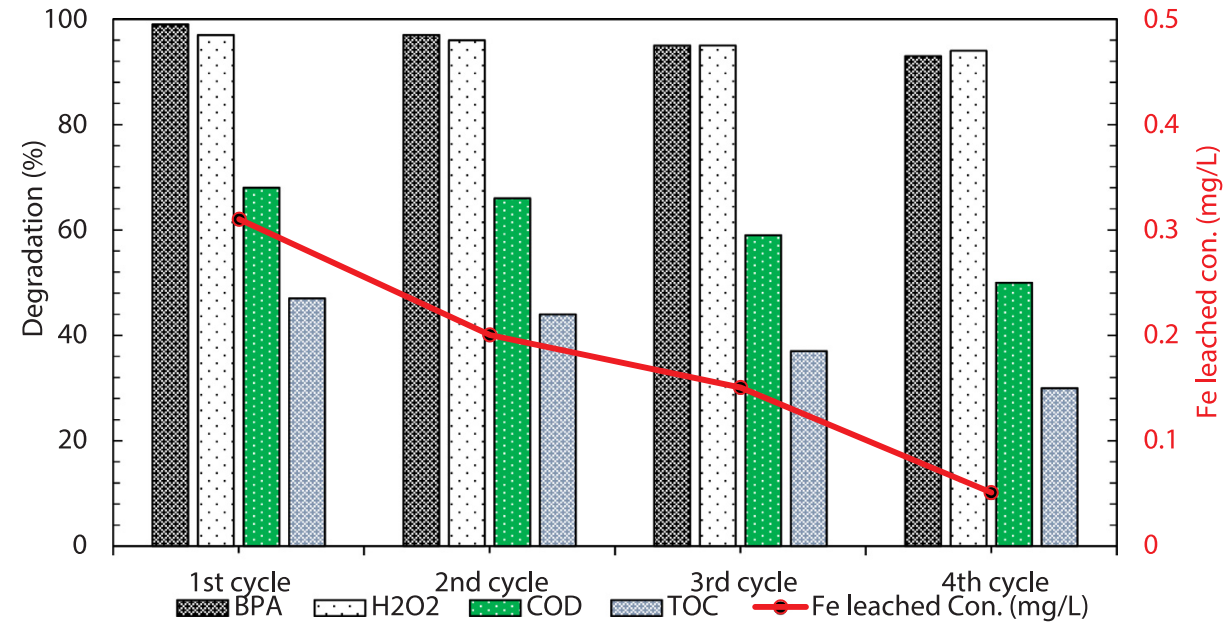

Fig. 9. The reusability of the magnetite TNT/CNT nanocomposite in the CWPO runs after $240 \mathrm{~min}$ for BPA, $\mathrm{H}_{2} \mathrm{O}_{2}$, COD and TOC degradation and concentrations of iron leached in four consecutive CWPO runs under the experimental optimum conditions $\quad\left(\mathrm{pH}=6.30, \quad\left[\mathrm{H}_{2} \mathrm{O}_{2}\right]_{0}=2.5 \mathrm{~g} / \mathrm{L}\right.$, $\mathrm{BPA}=50 \mathrm{mg} / \mathrm{L}, \mathrm{T}=70^{\circ} \mathrm{C} \quad$ and catalyst loading $=100 \mathrm{mg} / \mathrm{L}$ ). study. However, after 4 consecutive runs, the COD and TOC removal deceased to 50 and $30 \%$, respectively. Considering the presence of high levels of organic compounds in the PCW, it can be concluded that the CWPO shows a relatively acceptable performance in the reduction of organic pollutants in the PCW. This reduction in the performance of CWPO can be ascribed to (a) reduction of reactive oxidizing species by accumulation of organic pollutants/intermediates at the surface of the catalyst, (b) deactivation of the active sites on the surface of the nanocomposite, subsequently reducing the surface catalytic activity, (c) strong competitive reaction between parent pollutants and intermediates by-products for $\mathrm{HO}^{-}$radicals and (d) reduction of possible homogenous contribution due to the Fe leached into the reaction solution. Moreover, this stability of the nanocomposite can be related to the good stability against leaching of iron species, which is considered as the major reason for catalyst deactivation $[23,24,59]$. The highest and lowest dissolved Fe content was in the range $0.31-0.05 \mathrm{mg} / \mathrm{L}$, as corresponding to the 1 st and 4 th cycle, respectively. The maximum value of Fe leached in the aqueous solution $(0.31 \mathrm{mg} / \mathrm{L})$ was obtained in the first cycle, highlighting the compliance with legislation regarding the discharge of the treated stream into surface water resources, which is 10 -fold and 6-fold lower than the maximum contamination level for iron legislated by the DOE of Iran (the Islamic republic) $(3 \mathrm{mg} / \mathrm{L})$ and European Union (EU) Directives (2 mg/L), respectively [60].

\subsection{Mineralization and biodegradability assessment}

Qualitative GC/MS analysis was performed to identify the organic pollutants present in PCW before and after the CWPO experiments using the magnetite TNT/CNT nanocomposite under optimal operating conditions. In Table 2 is summarized the profile of the main organic pollutants identified, their change during degradation, their area, reduction and chemical structure in the raw PCW and in the treated effluent. As can be observed in Fig. 10a and Table 2, various types of toxic organic pollutants, such as BPA and other phenolic substances, were identified in the raw PCW. As shown in Fig. 10a, it is confirmed that the relative abundance of organic pollutants in the treated PCW decreased clearly after 240 min treatment by CWPO when compared with the raw PCW. This reveals that the CWPO process is an effective technique for the decomposition of recalcitrant and toxic organic pollutants. As can be seen in Table 2, the item 4 assigned to BPA (retention time $=17.69 \mathrm{~min}$ ) was removed completely by CWPO from the treated PCW. With respect to Table 2, some compounds (items number 5, 6 and 12) shows higher concentration in the treated than in the untreated PCW, which in one hand, suggest that BPA and other organic pollutants present in the PCW may be decomposed to this type of intermediates by-products (shown in BOLD in Table 2). On the other hand, under the experimental optimal conditions used, these formed intermediate byproducts have difficulty to be more oxidized compared to their parent compounds. Based on the qualitative GC/MS analysis, it is found that low molecular weight carboxylic acids, including propanoic acid,

Table 2

The profile of the main organic compounds identified in the PCW effluent using qualitative GC/MS analysis.

\begin{tabular}{|c|c|c|c|c|c|}
\hline \multirow{2}{*}{$\begin{array}{l}\text { Item code in GC/MS } \\
\text { graph }\end{array}$} & \multirow[t]{2}{*}{ Retention time (min) } & \multirow[t]{2}{*}{ Chemicals } & \multicolumn{2}{|c|}{ Area $\left(\begin{array}{ll}1 & 0^{4}\end{array}\right)$} & \multirow[t]{2}{*}{ Removal Efficiency (\%) } \\
\hline & & & Untreated & Treated & \\
\hline 1 & 14.73 & 2,4-Dichlorophenol & 1.96 & 1.41 & 28.06 \\
\hline 2 & 15.75 & 4,6-Dichlorophenol & 3.31 & 2.35 & 29 \\
\hline 3 & 17.69 & Bisphenol, tert-butyldimethylsilyl ether & 0.01 & 0.0 & 100 \\
\hline 4 & 18.31 & Phenol, 4-(1,1-dimethylethyl) & 0.15 & 0.17 & - \\
\hline 5 & 18.75 & 2-Chloro-4-hydroxybenzonitrile 1,2,4-Trimethoxybenzene & 0.16 & 0.44 & - \\
\hline 6 & 20.22 & 2,4,6-trichloro- phenol & 58.04 & 45.60 & 21 \\
\hline 7 & 22.14 & 2-Bromo-4,6-Dichlorophenol Thiophene & 1.69 & 0.85 & 49 \\
\hline 8 & 22.31 & 2-Bromo-4,6-Dichlorophenol Thiophene & 1.56 & 0.97 & 37 \\
\hline 9 & 23.94 & Phenol, 2,4-bis(1,1-dimethylethyl) & 12.26 & 22.21 & - \\
\hline 10 & 24.13 & 2,6-Dichloro-4-(1,1-dimethylethyl) phenol & 1.39 & 0.08 & 94 \\
\hline 11 & 26.93 & 2H-2,4a-Methanonaphthalene, 1,3,4, 5,6,7-hexahydro-1,1,5,5-tetramethy 1- & 0.16 & 0.01 & 93 \\
\hline 12 & 27.50 & $\begin{array}{l}\text { Silane, [[4-[1,2-bis[(trimethylsilyl)oxy]ethyl]-1,2-phenylene]bis(ox y)]bis } \\
\text { [trimethyl- }\end{array}$ & 0.62 & 0.16 & 74 \\
\hline 13 & 29.57 & 3,5-di-tert-Butyl-4-hydroxybenzaldehyde & 0.79 & 0.4 & 49 \\
\hline 14 & 31.67 & 1,2-Benzenedicarboxylic acid, bis(2-methylpropyl) ester & 0.96 & 0.08 & 91 \\
\hline 15 & 32.59 & 2,4,6-Trichlorophenol-Trimethyl-Silyl-Ether & 1.16 & 0.1 & 91 \\
\hline
\end{tabular}




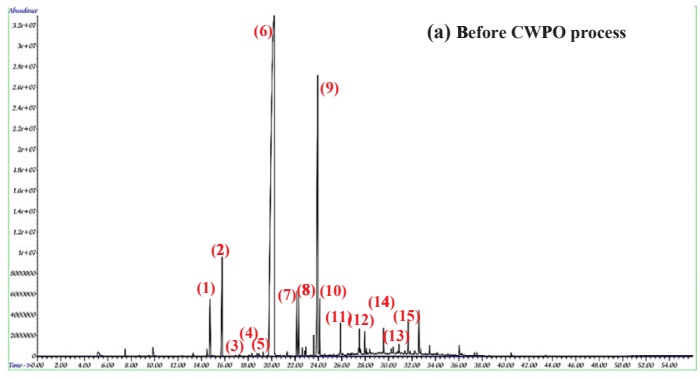

Fig. 10. (a) Qualitative GC/MS analysis to determine the main organic pollutants in the PCW, (b) COD and TOC reduction and (c) the biodegradability index i.e., $\mathrm{BOD}_{5} / \mathrm{COD}$ ratio, values of AOS and COS, before and after the CWPO process under optimal conditions $\quad\left(\mathrm{pH}=6.30, \quad\left[\mathrm{H}_{2} \mathrm{O}_{2}\right]_{0}=2.5 \mathrm{~g} / \mathrm{L}\right.$, $\mathrm{T}=70{ }^{\circ} \mathrm{C}$ and catalyst loading $=100 \mathrm{mg} /$ L).

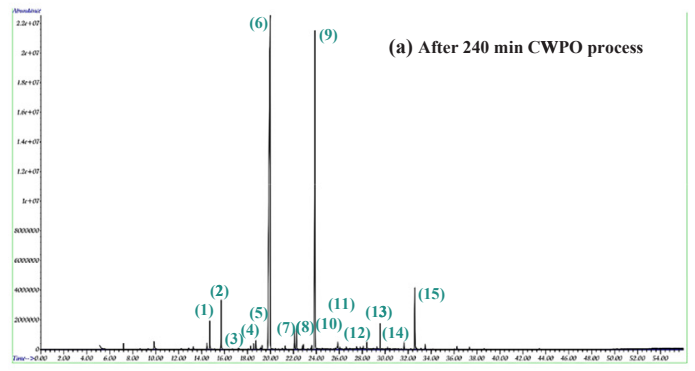

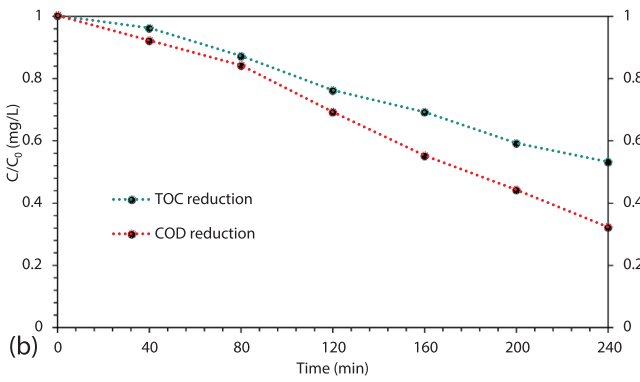

butanoic acid, ethanol, benzenedicarboxylic acid, oxalic acid, methoxyacetic acid, benzeneacetic acid, propionic acid, pentadecanoic acid and hexadecanoic acid, are present in the treated PCW as refractory byproducts. Similar studies reported that the low molecular weight carboxylic acids are the predominant compounds in the degradation process of organic matter after the CWPO process [4,22,23,35,36]. Therefore, it can be concluded that BPA and/or other organic pollutants in the PCW degrade to smaller and biodegradable compounds by CWPO process.

In the present study, although complete BPA degradation was obtained by CWPO process under the optimum conditions $(\mathrm{pH}=6.30$, $\left[\mathrm{H}_{2} \mathrm{O}_{2}\right]_{0}=2.5 \mathrm{~g} / \mathrm{L}$, and $\mathrm{T}=70^{\circ} \mathrm{C}$ and catalyst loading $=100 \mathrm{mg} / \mathrm{L}$ ), the COD and TOC reduction achieved $68.78 \%$ and $47.14 \%$, respectively (as shown in Fig. 10b). This may be due to the fact that generally real wastewater, especially the PCW considered in the present study, contains high levels of recalcitrant pollutants that cannot complete its degradation in the optimum conditions of the CWPO process. It is typically accepted that in AOPs such as CWPO the attack of HO to the organic pollutant resulted in the degradation of organic matter to their intermediates by-products and that by prolonging the CWPO process, ring opening of the phenolic compounds, such as BPA, occurs leading to the formation of low molecular weight carboxylic acids. These intermediate by-products usually require long retention times to be further oxidized to produce $\mathrm{H}_{2} \mathrm{O}$ and $\mathrm{CO}_{2}[1,4,12,21-23,36]$. On contrary, the low molecular weight carboxylic acids are the suitable substrate for biological treatment. Therefore, in the present study, as given in Fig. 10a and Table 2, the CWPO process after $240 \mathrm{~min}$ is capable to decompose the recalcitrant organic pollutants present in PCW to smaller compounds, such as low molecular weight carboxylic acids. Therefore, in the following section the biodegradability assessment of the treated PCW was performed.
The biodegradability of the PCW treated by CWPO was evaluated by the indirect analysis, i.e., biodegradability index, including $\mathrm{BOD}_{5} / \mathrm{COD}$ ratio, values of $A O S$ and $C O S$. The $\mathrm{BOD}_{5} / \mathrm{COD}$ ratio is widely accepted as an indicator of the biological treatability of the wastewater. When this ratio is 0.4 or larger it is considered that the wastewater contains biodegradable compounds and that it is treatable by means of biological treatment.

On the contrary, if the $\mathrm{BOD}_{5} / \mathrm{COD}$ ratio is below 0.4 , it indicates the presence of toxic compounds in the effluent, which is considered to be not biodegradable or acclimated micro-organisms being required for its biological treatment [61]. The values of AOS and COS, as calculated based on Eqs. (21) and (22), are both ranging from -4 for methane as the most reduced state of carbon to +4 for carbon dioxide as the most oxidized state of carbon $[1,13]$.

$\mathrm{AOS}=4-1.5[\mathrm{COD} / \mathrm{TOC}]$

$\operatorname{COS}=4-1.5\left[\mathrm{COD} / \mathrm{TOC}_{\mathrm{i}}\right]$

where, COD, TOC $\mathrm{i}_{\mathrm{i}}$ and TOC are the COD concentration at time $\mathrm{t}(\mathrm{mg}$ $\mathrm{O}_{2} / \mathrm{L}$ ), and the initial TOC concentration and TOC concentration at time $\mathrm{t}(\mathrm{mg} \mathrm{C} / \mathrm{L})$, respectively. According to Table 1 , the $\mathrm{BOD}_{5} / \mathrm{COD}$ ratio of the raw PCW was 0.15, suggesting that the raw PCW could not be treated by conventional biological treatments. In order to determine the influence of the CWPO process on the biodegradability of the PCW, the $\mathrm{BOD}_{5} / \mathrm{COD}$ and TOC of the treated PCW was investigated to calculate the $\mathrm{BOD}_{5} / \mathrm{COD}$ ratio, and $\mathrm{AOS}$ and $\mathrm{COS}$. The obtained results are depicted in Fig. 10c. The $\mathrm{BOD}_{5}$ of the treated PCW by CWPO during $240 \mathrm{~min}$ decreased slightly and its value was decreased to $220 \mathrm{mg} / \mathrm{L}$. This phenomena could be ascribed to the performance of CWPO for degradation of organic compounds to simple biodegradable compounds, such as low weight carboxylic acids (e.g. acetic acid). At the 
same time, the COD of the treated PCW decreased from $1650 \mathrm{mg} / \mathrm{L}$ to $515 \mathrm{mg} / \mathrm{L}$ ( $68.78 \%$ reduction) during $240 \mathrm{~min}$. Accordingly, the $\mathrm{BOD}_{5} /$ COD ratio of the raw and treated PCW were 0.10 and 0.43 , respectively, indicating a 4-fold increase in the $\mathrm{BOD}_{5} / \mathrm{COD}$ ratio of the treated PCW. This indicate that the treated PCW is much more biodegradable when compared with the raw PCW, due mainly to the degradation/reducing of the recalcitrant organic pollutants and the production of more biodegradable compounds. It is widely accepted that when the wastewater is considered to be treatable by biological treatment, its $\mathrm{BOD}_{5} / \mathrm{COD}$ ratio is in the range of $0.3-0.5$ [61]. As observed in Fig. 10c, it is clearly shown that both AOS and COS values significantly increased to 2.26 and 3.08 respectively, by the CWPO process which indicate the high improvement of biodegradability of treated PCW, suggesting to use a biological wastewater treatment in a further purification process.

\section{Conclusion}

In the present study, a magnetite TNT/CNT nanocomposite was developed, characterized and applied towards oxidative degradation of organic pollutants. The developed catalyst shows high catalytic activity in the CWPO in terms of BPA degradation alone or present in the PCW. The influence of operating parameters, including solution $\mathrm{pH}, \mathrm{H}_{2} \mathrm{O}_{2}$ dosage, reaction temperature and catalyst loading was optimized in the CWPO process for degradation of BPA in the PCW. The COD, $\mathrm{BOD}_{5}$ and TOC of the PCW was also considered in this work and the COD and TOC reduction values of $68.78 \%$ and $47.14 \%$, were achieved, respectively. The biodegradability of the treated PCW increased during the CWPO process, a 4-fold increase of the $\mathrm{BOD}_{5} / \mathrm{COD}$ ratio being obtained. The stability and reusability of the nanocomposite was proved in the CWPO by four consecutive runs in terms of its catalytic activity. Finally, it can be concluded that the CWPO process using the magnetite TNT/CNT nanocomposite shows the applicability of this process to the treatment of highly toxic and high saline petrochemical wastewater such as PCW.

\section{Conflict of interests}

The authors of this research declare no conflict of interest.

\section{Acknowledgments}

The present work was a part of a Ph.D. thesis of Seyyed Abbas Mirzaee in Ahvaz Jundishapur University of Medical Sciences (AJUMS), Ahvaz, Iran. This study was financially supported by Environmental Technologies Research Center, AJUMS (grant No. ETRC-9612). The authors would also like to grateful to Mrs. Atashin, Mrs. Azizi and Mrs. Khodadadi for running the TOC, HPLC and GC/MS analyzer, respectively.

\section{Appendix A. Supplementary data}

Supplementary data to this article can be found online at https:// doi.org/10.1016/j.cej.2019.03.202.

\section{References}

[1] M. Ahmadi, B. Kakavandi, N. Jaafarzadeh, A. Akbar, Babaei, Catalytic ozonation of high saline petrochemical wastewater using PAC@FeIIFe2IIIO4: optimization, mechanisms and biodegradability studies, Sep. Purif. Technol. 177 (2017) 293-303.

[2] S.A. Mirzaee, N. Jaafarzadeh, S. Jorfi, H.T. Gomes, M. Ahmadi, Enhanced degradation of Bisphenol A from high saline polycarbonate plant wastewater using wet air oxidation, Process Saf. Environ. Prot. 120 (2018) 321-330.

[3] S. Jorfi, S. Pourfadakari, M. Ahmadi, Electrokinetic treatment of high saline petrochemical wastewater: evaluation and scale-up, J. Environ. Manage. 204 (2017) 221-229.

[4] B. Erjavec, R. Kaplan, P. Djinović, A. Pintar, Catalytic wet air oxidation of bisphenol A model solution in a trickle-bed reactor over titanate nanotube-based catalysts, Appl. Catal. B 132-133 (2013) 342-352.

[5] J. Michałowicz, Bisphenol A-sources, toxicity and biotransformation, Environ. Toxicol. Pharmacol. 37 (2014) 738-758.
[6] D.D. Seachrist, K.W. Bonk, S.-M. Ho, G.S. Prins, A.M. Soto, R.A. Keri, A review of the carcinogenic potential of bisphenol A, Reprod. Toxicol. 59 (2016) 167-182.

[7] H. Melcer, G. Klečka, Treatment of wastewaters containing bisphenol A: state of the science review, Water Environ. Res. 83 (2011) 650-666.

[8] N. Alavi, H. Salamifar, M.J. Mohammadi, M. Almasian, A.H. Hassani, M. Majlesi, S.A. Mirzaee, Removal of ammonium and organic carbon from leachate by the anammox process in a fixed bed bioreactor, Desalin. Water Treat. 99 (2017) $330-337$.

[9] H.C. Alexander, D.C. Dill, L.W. Smith, P.D. Guiney, P. Dorn, Bisphenol A: acute aquatic toxicity, Environ. Toxicol. Chem. 7 (1988) 19-26.

[10] Z. Noorimotlagh, S.A. Mirzaee, M. Ahmadi, N. Jaafarzadeh, F. Rahim, The possible DNA damage induced by environmental organic compounds: the case of Nonylphenol, Ecotoxicol. Environ. Saf. 158 (2018) 171-181.

[11] R.S. Ribeiro, Z. Frontistis, D. Mantzavinos, D. Venieri, M. Antonopoulou, I. Konstantinou, A.M.T. Silva, J.L. Faria, H.T. Gomes, Magnetic carbon xerogels for the catalytic wet peroxide oxidation of sulfamethoxazole in environmentally relevant water matrices, Appl. Catal. B 199 (2016) 170-186.

[12] M. Ahmadi, H. Rahmani, A. Takdastan, N. Jaafarzadeh, A. Mostoufi, A novel catalytic process for degradation of Bisphenol A from aqueous solutions: a synergistic effect of nano-Fe3O4@Alg-Fe on O3/H2O2, Process Saf. Environ. Prot. 104 (2016) 413-421.

[13] Z. Noorimotlagh, I. Kazeminezhad, N. Jaafarzadeh, M. Ahmadi, Z. Ramezani, S. Silva Martinez, The visible-light photodegradation of nonylphenol in the presence of carbon-doped TiO2 with rutile/anatase ratio coated on GAC: Effect of parameters and degradation mechanism, J. Hazard. Mater. 350 (2018) 108-120.

[14] I.F. Mena, E. Diaz, J.J. Rodriguez, A.F. Mohedano, CWPO of bisphenol A with iron catalysts supported on microporous carbons from grape seeds activation, Chem. Eng. J. 318 (2017) 153-160.

[15] M. Munoz, F.J. Mora, Z.M. De Pedro, S. Alvarez-Torrellas, J.A. Casas, J.J. Rodriguez, Application of CWPO to the treatment of pharmaceutical emerging pollutants in different water matrices with a ferromagnetic catalyst, J. Hazard. Mater. 331 (2017) 45-54.

[16] M. Ahmadi, S. Jorfi, R. Kujlu, S. Ghafari, R. Darvishi Cheshmeh Soltani, N. Jaafarzadeh Haghighifard, A novel salt-tolerant bacterial consortium for biodegradation of saline and recalcitrant petrochemical wastewater, J. Environ. Manage. 191 (2017) 198-208.

[17] R.D.C. Soltani, G. Shams Khoramabadi, H. Godini, Z. Noorimotlagh, The application of $\mathrm{ZnO} / \mathrm{SiO} 2$ nanocomposite for the photocatalytic degradation of a textile dye in aqueous solutions in comparison with pure ZnO nanoparticles, Desalin. Water Treat. 56 (2015) 2551-2558.

[18] H.T. Gomes, B.F. Machado, A. Ribeiro, I. Moreira, M. Rosário, A.M.T. Silva, J.L. Figueiredo, J.L. Faria, Catalytic properties of carbon materials for wet oxidation of aniline, J. Hazard. Mater. 159 (2008) 420-426.

[19] C.M. Domínguez, P. Ocón, A. Quintanilla, J.A. Casas, J.J. Rodriguez, Highly efficient application of activated carbon as catalyst for wet peroxide oxidation, Appl. Catal. B 140 (2013) 663-670.

[20] H.T. Gomes, S.M. Miranda, M.J. Sampaio, J.L. Figueiredo, A.M. Silva, J.L. Faria, The role of activated carbons functionalized with thiol and sulfonic acid groups in catalytic wet peroxide oxidation, Appl. Catal. B 106 (2011) 390-397.

[21] R.S. Ribeiro, R.O. Rodrigues, A.M. Silva, P.B. Tavares, A.M. Carvalho, J.L. Figueiredo, J.L. Faria, H.T. Gomes, Hybrid magnetic graphitic nanocomposites towards catalytic wet peroxide oxidation of the liquid effluent from a mechanical biological treatment plant for municipal solid waste, Appl. Catal. B 219 (2017) 645-657.

[22] R.S. Ribeiro, A.M.T. Silva, J.L. Figueiredo, J.L. Faria, H.T. Gomes, Removal of 2 nitrophenol by catalytic wet peroxide oxidation using carbon materials with different morphological and chemical properties, Appl. Catal. B 140-141 (2013) $356-362$.

[23] R.S. Ribeiro, A.M.T. Silva, J.L. Figueiredo, J.L. Faria, H.T. Gomes, Catalytic wet peroxide oxidation: a route towards the application of hybrid magnetic carbon nanocomposites for the degradation of organic pollutants. A review, Appl. Catal. B Environ. 187 (2016) 428-460.

[24] M. Munoz, Z.M. de Pedro, J.A. Casas, J.J. Rodriguez, Preparation of magnetitebased catalysts and their application in heterogeneous Fenton oxidation - A review, Appl. Catal. B 176-177 (2015) 249-265.

[25] Fritz Harber, J. Weiss, The catalytic decomposition of hydrogen peroxide by iron salts, Proc. R. Soc. Lond. Ser. A - Math. Phys. Sci. 147 (1934) 332-351.

[26] M.H. Do, N.H. Phan, T.D. Nguyen, T.T.S. Pham, V.K. Nguyen, T.T.T. Vu, T.K.P. Nguyen, Activated carbon/Fe3O4 nanoparticle composite: Fabrication, methyl orange removal and regeneration by hydrogen peroxide, Chemosphere 85 (2011) 1269-1276.

[27] N. Jaafarzadeh, B. Kakavandi, A. Takdastan, R.R. Kalantary, M. Azizi, S. Jorfi, Powder activated carbon/Fe 3 O 4 hybrid composite as a highly efficient heterogeneous catalyst for Fenton oxidation of tetracycline: degradation mechanism and kinetic, RSC Adv. 5 (2015) 84718-84728.

[28] J.A. Zazo, J.A. Casas, A.F. Mohedano, J.J. Rodríguez, Catalytic wet peroxide oxidation of phenol with a Fe/active carbon catalyst, Appl. Catal. B 65 (2006) $261-268$.

[29] S. Navalon, M. Alvaro, H. Garcia, Heterogeneous Fenton catalysts based on clays, silicas and zeolites, Appl. Catal. B 99 (2010) 1-26.

[30] S. Messele, O. Soares, J. Órfão, F. Stüber, C. Bengoa, A. Fortuny, A. Fabregat, J. Font, Zero-valent iron supported on nitrogen-containing activated carbon for catalytic wet peroxide oxidation of phenol, Appl. Catal. B 154 (2014) 329-338.

[31] H.T. Gomes, S.M. Miranda, M.J. Sampaio, A.M.T. Silva, J.L. Faria, Activated carbons treated with sulphuric acid: catalysts for catalytic wet peroxide oxidation, Catal. Today 151 (2010) 153-158. 
[32] F. Lücking, H. Köser, M. Jank, A. Ritter, Iron powder, graphite and activated carbon as catalysts for the oxidation of 4-chlorophenol with hydrogen peroxide in aqueous solution, Water Res. 32 (1998) 2607-2614.

[33] C.M. Domínguez, P. Ocón, A. Quintanilla, J.A. Casas, J.J. Rodriguez, Graphite and carbon black materials as catalysts for wet peroxide oxidation, Appl. Catal. B 144 (2014) 599-606.

[34] M.T. Pinho, A.M.T. Silva, N.A. Fathy, A.A. Attia, H.T. Gomes, J.L. Faria, Activated carbon xerogel-chitosan composite materials for catalytic wet peroxide oxidation under intensified process conditions, J. Environ. Chem. Eng. 3 (2015) 1243-1251.

[35] R.S. Ribeiro, A.M. Silva, L.M. Pastrana-Martínez, J.L. Figueiredo, J.L. Faria, H.T. Gomes, Graphene-based materials for the catalytic wet peroxide oxidation of highly concentrated 4-nitrophenol solutions, Catal. Today 249 (2015) 204-212.

[36] M.T. Pinho, H.T. Gomes, R.S. Ribeiro, J.L. Faria, A.M. Silva, Carbon nanotubes catalysts for catalytic wet peroxide oxidation of highly concentrated phenol solutions: towards process intensification, Appl. Catal. B 165 (2015) 706-714.

[37] Z. Noorimotlagh, S.A. Mirzaee, S.S. Martinez, S. Alavi, M. Ahmadi, N. Jaafarzadeh, Adsorption of textile dye in activated carbons prepared from DVD and CD wastes modified with multi-wall carbon nanotubes: Equilibrium isotherms, kinetics and thermodynamic study, Chem. Eng. Res. Des. 141 (2019) 290-301.

[38] T.S. Natarajan, J.Y. Lee, H.C. Bajaj, W.-K. Jo, R.J. Tayade, Synthesis of multiwall carbon nanotubes/TiO2 nanotube composites with enhanced photocatalytic decomposition efficiency, Catal. Today 282 (2017) 13-23.

[39] S. Nethaji, A. Sivasamy, A. Mandal, Preparation and characterization of corn cob activated carbon coated with nano-sized magnetite particles for the removal of $\mathrm{Cr}$ (VI), Bioresour. Technol. 134 (2013) 94-100.

[40] B. Kakavandi, A. Takdastan, N. Jaafarzadeh, M. Azizi, A. Mirzaei, A. Azari, Application of Fe3O4@ C catalyzing heterogeneous UV-Fenton system for tetracycline removal with a focus on optimization by a response surface method, J. Photochem. Photobiol. A 314 (2016) 178-188.

[41] T. Kasuga, M. Hiramatsu, A. Hoson, T. Sekino, K. Niihara, Titania nanotubes prepared by chemical processing, Adv. Mater. 11 (1999) 1307-1311.

[42] B.T. Erjavec, T. Tišler, R. Kaplan, A. Pintar, Titanate nanotubes as a novel catalyst for removal of toxicity and estrogenicity of Bisphenol A in the CWAO process, Ind. Eng. Chem. Res. 52 (2013) 12559-12566.

[43] Z.-R. Tang, F. Li, Y. Zhang, X. Fu, Y.-J. Xu, Composites of titanate nanotube and carbon nanotube as photocatalyst with high mineralization ratio for gas-phase degradation of volatile aromatic pollutant, J. Phys. Chem. C 115 (2011) 7880-7886.

[44] A. Payan, M. Fattahi, S. Jorfi, B. Roozbehani, S. Payan, Synthesis and characterization of titanate nanotube/single-walled carbon nanotube (TNT/SWCNT) porous nanocomposite and its photocatalytic activity on 4-chlorophenol degradation under UV and solar irradiation, Appl. Surf. Sci. 434 (2018) 336-350.

[45] APHA, Standard methods for the examination of water and wastewater, 20th ed., 2005.

[46] Y.W. Kang, M.-J. Cho, K.-Y. Hwang, Correction of hydrogen peroxide interference on standard chemical oxygen demand test, Water Res. 33 (1999) 1247-1251.

[47] Y. Wang, H. Sun, H.M. Ang, M.O. Tadé, S. Wang, Synthesis of magnetic core/shell carbon nanosphere supported manganese catalysts for oxidation of organics in water by peroxymonosulfate, J. Colloid Interface Sci. 433 (2014) 68-75.

[48] Y. Wang, H. Sun, H.M. Ang, M.O. Tadé, S. Wang, Magnetic Fe3O4/carbon sphere/ cobalt composites for catalytic oxidation of phenol solutions with sulfate radicals, Chem. Eng. J. 245 (2014) 1-9.

[49] B. Kakavandi, M. Jahangiri-rad, M. Rafiee, A.R. Esfahani, A.A. Babaei, Developmen of response surface methodology for optimization of phenol and p-chlorophenol adsorption on magnetic recoverable carbon, Microporous Mesoporous Mater. 231 (2016) 192-206.

[50] B.K. Vijayan, N.M. Dimitrijevic, D. Finkelstein-Shapiro, J. Wu, K.A. Gray, Coupling titania nanotubes and carbon nanotubes to create photocatalytic nanocomposites, ACS Catal. 2 (2012) 223-229.

[51] S. Yang, X. Li, W. Zhu, J. Wang, C. Descorme, Catalytic activity, stability and structure of multi-walled carbon nanotubes in the wet air oxidation of phenol, Carbon 46 (2008) 445-452.

[52] S. Zhang, X. Zhao, H. Niu, Y. Shi, Y. Cai, G. Jiang, Superparamagnetic Fe3O4 nanoparticles as catalysts for the catalytic oxidation of phenolic and aniline compounds, J. Hazard. Mater. 167 (2009) 560-566.

[53] Z. Noorimotlagh, R. Darvishi Cheshmeh Soltani, G. Shams Khorramabadi, H. Godini, M. Almasian, Performance of wastewater sludge modified with zinc oxide nanoparticles in the removal of methylene blue from aqueous solutions, Desalin. Water Treat. 57 (2016) 1684-1692.

[54] M. Martin-Martinez, M.F.F. Barreiro, A.M. Silva, J.L. Figueiredo, J.L. Faria, H.T. Gomes, Lignin-based activated carbons as metal-free catalysts for the oxidative degradation of 4-nitrophenol in aqueous solution, Appl. Catal. B 219 (2017) 372-378.

[55] A. Takdastan, B. Kakavandi, M. Azizi, M. Golshan, Efficient activation of peroxymonosulfate by using ferroferric oxide supported on carbon/UV/US system: a new approach into catalytic degradation of bisphenol A, Chem. Eng. J. 331 (2018) 729-743.

[56] N. Jaafarzadeh, F. Ghanbari, M. Ahmadi, Efficient degradation of 2,4-dichlorophenoxyacetic acid by peroxymonosulfate/magnetic copper ferrite nanoparticles/ozone: a novel combination of advanced oxidation processes, Chem. Eng. J. 320 (2017) 436-447.

[57] J. Sharma, I.M. Mishra, D.D. Dionysiou, V. Kumar, Oxidative removal of Bispheno A by UV-C/peroxymonosulfate (PMS): kinetics, influence of co-existing chemicals and degradation pathway, Chem. Eng. J. 276 (2015) 193-204.

[58] R. Li, X. Jin, M. Megharaj, R. Naidu, Z. Chen, Heterogeneous Fenton oxidation of 2,4-dichlorophenol using iron-based nanoparticles and persulfate system, Chem. Eng. J. 264 (2015) 587-594.

[59] F. Arena, R. Di Chio, B. Gumina, L. Spadaro, G. Trunfio, Recent advances on wet air oxidation catalysts for treatment of industrial wastewaters, Inorg. Chim. Acta 431 (2015) 101-109.

[60] Departemet of Environment (DOE), Rules and Regulations for Environmetal protection in Iran, in, Tehran, Iran, 2001.

[61] G. Tchobanoglous, F.L. Burton, H.D. Stensel, Wastewater Engineering: Treatment and Reuse, 4th ed., Metcalf \& Eddy, Inc., McGraw-Hill companies, New York, 2003 International Edition ed.. 